University of New Hampshire

University of New Hampshire Scholars' Repository

Faculty Publications

Summer 6-2020

\title{
When to Make the Sensory Social: Registering in Face-to-Face Openings
}

Danielle M. Pillet-Shore

University of New Hampshire - Main Campus, danielle.pillet-shore@unh.edu

Follow this and additional works at: https://scholars.unh.edu/faculty_pubs

Part of the Anthropological Linguistics and Sociolinguistics Commons, Cognition and Perception Commons, Discourse and Text Linguistics Commons, Interpersonal and Small Group Communication Commons, Social Psychology Commons, and the Social Psychology and Interaction Commons

\section{Recommended Citation}

Pillet-Shore, Danielle. (2020/2021). When to Make the Sensory Social: Registering in Face-to-Face Openings. Symbolic Interaction.

This Article is brought to you for free and open access by University of New Hampshire Scholars' Repository. It has been accepted for inclusion in Faculty Publications by an authorized administrator of University of New Hampshire Scholars' Repository. For more information, please contact Scholarly.Communication@unh.edu. 


\title{
When to Make the Sensory Social: Registering in Face-to-Face Openings
}

\author{
Danielle Pillet-Shore (1) \\ University of New Hampshire, USA
}

\begin{abstract}
This article analyzes naturally occurring video-recorded openings during which participants make the sensory social through the action of registering - calling joint attention to a selected, publicly perceivable referent so others shift their sensory attention to it. It examines sequence-initial actions that register referents for which a participant is regarded as responsible. Findings demonstrate a systematic preference organization which observably guides when and how people initiate registering sequences sensitive to ownership of, and displayed stance toward, the target referent. Analysis shows how registering an owned referent achieves intersubjectivity and puts involved participants' face, affiliation, and social relationship on the line. A video abstract is available at https://youtu.be/rNL70vawG3o

Keywords: joint attention, noticing, intersubjectivity, multi-modal conversation analysis, video, openings, preference, face, self
\end{abstract}

\section{INTRODUCTION}

Human experience is grounded in its shared nature (Moore and Dunham 1995). To "construct and coordinate the shared social realities that comprise everyday life" (Bruner 1995:11-12), we must be able to establish joint attention and intersubjectivity, knowing together that we are attending to and understanding the meaning of the same referent (Carpenter and Liebal 2011:159-60; Goffman 1967:34; Scheff 2005:156-57, 160-61; Tomasello 1995). This article examines a basic and pervasive communicative action through which people establish joint attention and intersubjectivity: the action of registering. Registering refers to the linguistic and embodied ways that people interacting face-to-face ${ }^{1}$ call joint attention to a selected publicly perceivable referent so copresent others shift their attention to it (Pillet-Shore 2017, 2018a; Schegloff 2007). Through this action, interactional coparticipants invoke a

Direct all correspondence to Dr. Danielle Pillet-Shore, Department of Communication, University of New Hampshire, Horton Social Science Center, 20 Academic Way, Durham, NH 03824; e-mail: danielle.pillet-shore@unh.edu.

Symbolic Interaction, (2020), p. n/a, ISSN: 0195-6086 print/1533-8665 online. (C) 2020 Society for the Study of Symbolic Interaction. All rights reserved.

DOI: 10.1002/SYMB.481 
present, personal perceptual experience so they may immediately share it, thereby making the sensory social.

An opportune site for (producing and examining) the social action of registering is the opening phase of face-to-face interaction, since the beginning of a copresent encounter is a time of heightened exposure to novel sensory stimuli and heightened self- and other- awareness and attentiveness (Pillet-Shore 2008, 2018a). During openings, participants observably display that they are monitoring for diverse and distributed manifestations of the self (cf. Scheff 2005:147-49), including presentation of participants' bodies (e.g., how persons look, smell, sound) as well as participants' self-extensions, like living quarters (e.g., how a person's residence looks and smells; Pillet-Shore 2017, 2018a; Schegloff 2007:86-88) and other beings for whom one is regarded as responsible (e.g., pets, young children; Pillet-Shore 2017, 2018a). Based on a conversation analytic (CA) examination of naturally occurring video-recorded openings, this article examines sequence-initial registering actions, closely analyzing when people choose to audibly point to a publicly perceivable referent, including visible, audible, palpable, and olfactible features ${ }^{2}$ of the setting and its participants (Pillet-Shore 2018a).

Excerpts 1 and 2 exemplify this article's focal phenomenon (with an arrow -> pointing to the sequence-initial registering utterance, and bold indicating actions constituting the larger registering sequence). ${ }^{3}$ In Excerpt 1, Jill is entering her friend Gina's apartment. While still at the door's threshold (Figure 1a), Jill delivers a registering utterance starting at line 6:
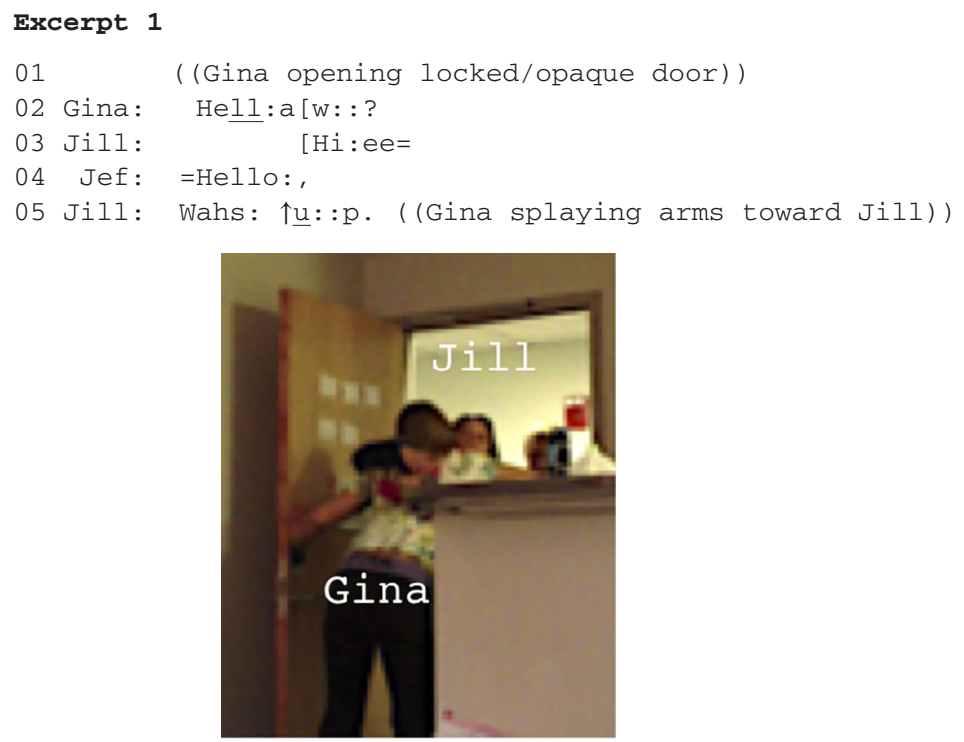

Figure 1a

+figure $1 \mathrm{a}$

$06 \mathrm{Jill}:$-> Mm: :=It smells+ so go:od in he[re.

07 Gina: ((Gina, Jill hugging)) [Welçom:e, 


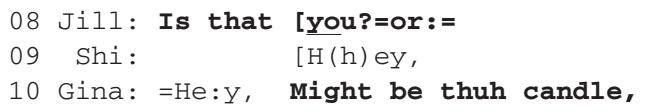

Audibly pointing to her own sensorial experience of perceiving a "go:od" smell via the "evidential" verb (Chafe and Nichols 1986) "smells," Jill thereby calls others' attention to this olfactible referent.

When a person initially registers a referent apparently using one sense, that action can occasion participants to successively engage in a multi-sensorial experience with that referent. Excerpt 2 shows resident Sally enthusiastically greeting her Mom at the entrance to her apartment. As Sally lifts her head from Mom's shoulder so she can gaze at her face, she delivers a registering utterance starting at line 8 , audibly pointing to her visual perception (via evidential verb "lo(h)oks"; Chafe and Nichols 1986) of Mom's change in hairstyle since they last saw one another (lines 14-15, 18-19). During this time, Sally concurrently touches Mom's hair (Figure 2c,d), an action Mom mirrors by then touching her own hair (Figure 2d):

\section{Excerpt 2}

$\begin{array}{ll}01 & \text { ( Sally opening locked/opaque door)) } \\ 02 \text { Mom: } & {[£ \uparrow H i: e:: \text { ((Sally shoots arms up in "V")) }} \\ 03 \text { Sally: } & \text { [.hhh! Ehihh! heh +heh } \\ & \text { +figure 2a }\end{array}$

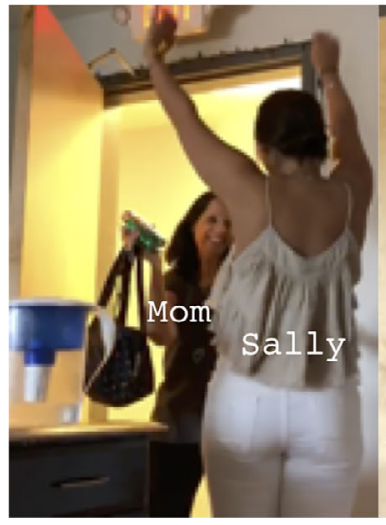

Figure 2a

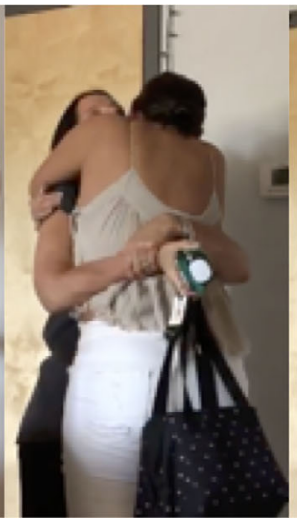

Figure 2b

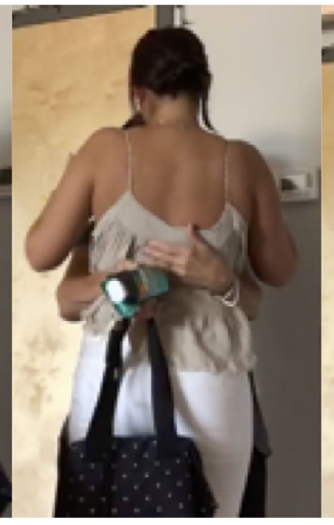

Figure 25

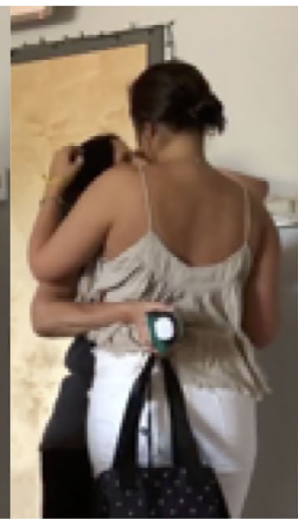

Figure 2d 


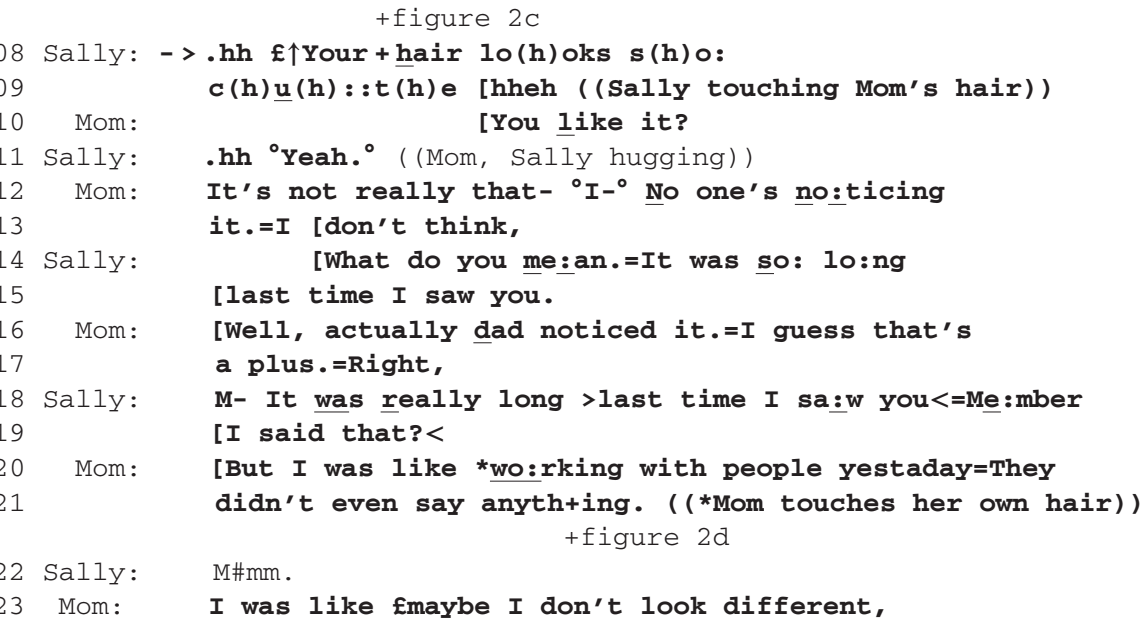

Excerpt 2 thus shows how Sally's action of calling attention to a visible and palpable referent engenders a joint multi-sensorial experience ${ }^{4}$ (cf. Leichty 1975; Mondada 2012, 2019). Furthermore, this sequence shows a participant's use of the vernacular metalinguistic term "noticing" (line 12; see "Background") to refer to the action that this article terms registering, evidencing participants' orientation to the importance of this social action being done - or not done (lines 12-23) between incumbents of certain relationship categories (Pomerantz and Mandelbaum 2005; e.g., mother-adult daughter [lines 8-15; 18-19], husband-wife [lines 16-17], and co-workers [lines 20-21]) who may be treated as accountable for performing this action in everyday encounters.

\section{Background}

Much of the research on joint attention has been conducted in laboratory settings, ${ }^{5}$ primarily focusing upon human infants' abilities to follow an adult's eye gaze to an inanimate object (e.g., Carpenter and Liebal 2011; Moore and Dunham 1995). Noting that these psychological studies take "as unproblematic how parties coordinate their actions in the first place such that a joint attention event is achieved, and moreover, achieved for a particular social purpose," Kidwell and Zimmerman (2007:594) examine episodes of video-recorded, naturally occurring interaction within infant-toddler daycare centers, explicating how children aged $1-2 \frac{1}{2}$ years coordinate joint attention to an object.

There is ample interaction analytic literature investigating recorded encounters in which adult participants call joint attention to a publicly perceivable referent. The many contributions to this body of work, however, use different terms to refer to what is apparently the same (or at least very similar and overlapping) underlying social action. In addition to CA work's use of the term registering (Hoey 2018; Pillet-Shore 2017, 2018a; Schegloff 2007:82-88; Steensig 2015), other extant terms 
include noticing (Goodwin and Goodwin 2012; Kääntä 2014; Keisanen 2012; Laanesoo and Keevallik 2017; Sacks 1992; Schegloff 1988, 2007; Stivers and Rossano 2010:9; Szymanski 1999), announcing (Schegloff 2007; Stivers and Rossano 2010:9), setting talk (Maynard and Zimmerman 1984:304), comments on the physical surroundings (Keevallik 2018), and local sensitivity to elements in participants' field of perception (Bergmann 1990:207). ${ }^{6}$ Among these, the term noticing is most common and recognizable, since the earliest CA works (Sacks 1992 II:87-97; Schegloff 1988:119-31) used this vernacular metalinguistic term (Levinson 2013:122) to invoke and parlay "the reader's experience" without having to offer a definition, explanation, or evidence (Schegloff 2007:88).

The fact that scholars have used disparate terms poses a problem for scientific consistency, compromising our ability to build upon past research and refine and advance our understanding of how and when people do this ubiquitous and versatile (Albert and Smith 2018) communicative action. Furthermore, extant work has not clearly explicated what might make an action recognizable (to participants, and then to analysts) as "noticing" versus "announcing" a here-and-now referent.

In prior work most directly relevant to the present investigation, Schegloff (2007:82-88) uses the terms "registering," "noticing," and "announcing":

In achieving the official and explicit registering of some feature of the environment of the interaction affiliated to or identified with one of the participants - and "positively valued" features in particular - there appears to be a preference for noticing-by-others over announcement-by-"self" (where "self" is the one characterized by the feature). (p. 82)

Consistent with Schegloff, the present research uses "registering" as an umbrella term encompassing the difficult to disaggregate actions of "noticing" and "announcing" (Pillet-Shore 2018a), since analysis of my data set shows that participants can register in a way that resists neat and defensible categorization as either "noticing" or "announcing." For instance, in Excerpt 3 shortly after Lilly enters her friends' apartment, already-present and situated resident Ryan registers a bug on the ceiling at line 7:

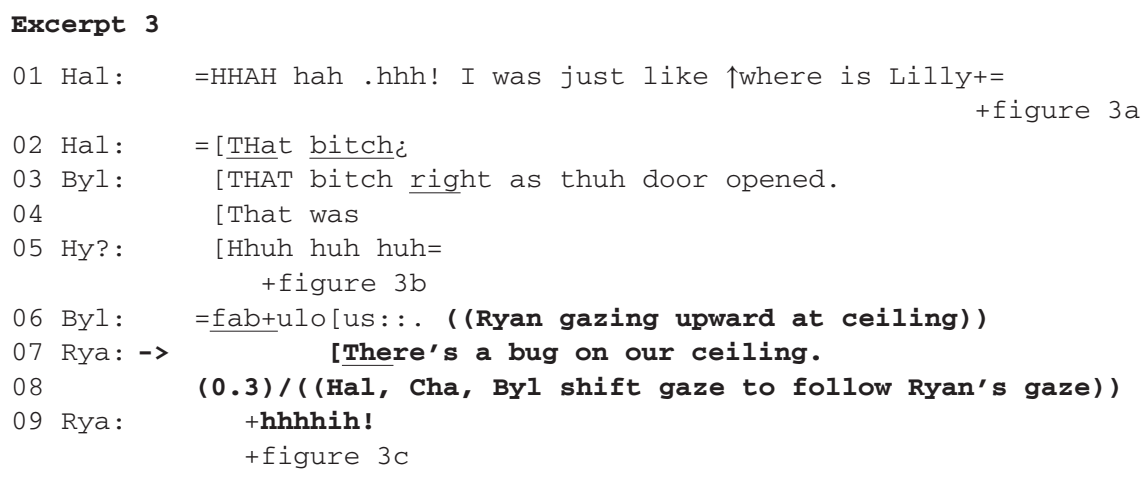




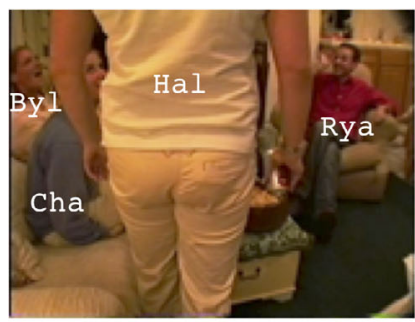

Figure $3 a$

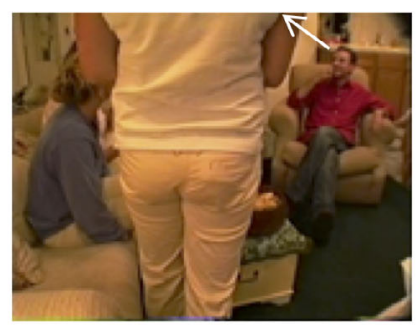

Figure $3 b$

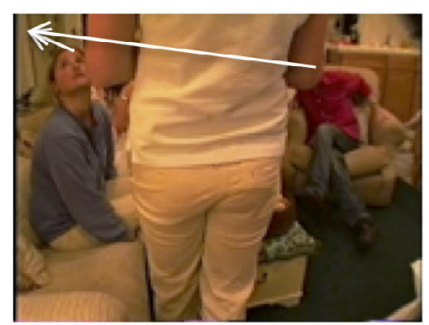

Figure 3c

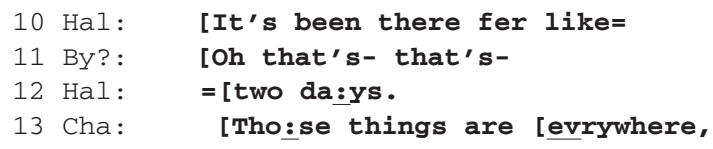

Ryan's registering actions, including his utterance, gaze (Figure 3b), and body lean (Figure 3c), occasion his coparticipants to suddenly shift their gaze and joint attention to follow Ryan's gaze to his selected, publicly perceivable referent (Figure 3c). But is Ryan noticing and/or announcing the bug? This article specifically does not try to disentangle these actions, the reasons for this becoming clear when we consider this issue further.

Past work implies that "noticing" is a recipient-directed (Keevallik 2018) and/or other-attentive action, whereas "announcing" is a self-attentive action. But how might that conceptual self/other distinction apply to Ryan's line 7? Moreover, past work also implies that, whereas "announcing" is done by speakers displaying a knowing epistemic stance, "noticing" applies when the referent is suddenly perceivable (which is often correlated with speakers displaying an unknowing-to-now-knowing epistemic stance, e.g., via turn-initial reaction token; Heritage 1984:286-87; Wilkinson and Kitzinger 2006). But how might this conceptual distinction apply to Ryan's line 7 , or more generally to cases when a participant does not (e.g., due to in-progress talk) interactionally register a target referent at the moment s/he perceives that referent? In the seconds leading up to line 7, Ryan's head and gazing movements suggest he may have first visually perceived the bug on the ceiling during Hal's utterance at line 1 (Figure 3a). At the same time, Ryan does not produce a reaction token, and he has been seated in his shared apartment with possible visual access to this communal referent for some time. Moreover, at lines 10 and 12, his roommate Hal sanctions him for his referent's lack of novelty.

Another exemplar resisting neat and defensible categorization as either "noticing" or "announcing," Excerpt 4 represents cases in my data set in which people register newcomers' arrivals, as Ann does at line 3:

\section{Excerpt 4}

01 Mik: I didn't do research on actual intimacy.=But I'm hoping 


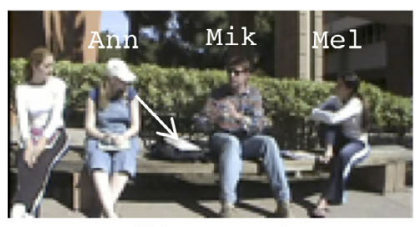

Figure $4 a$

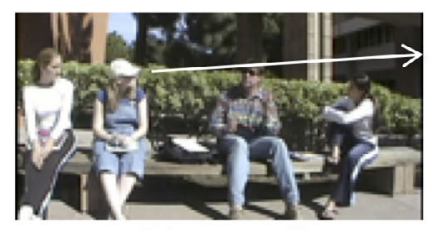

Figure $4 \mathrm{~b}$

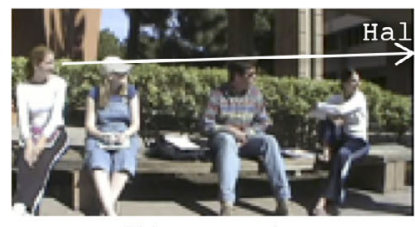

Figure $4 \mathrm{c}$

03 Ann: -> TThere she is, ((*Ann shifts gaze up to arriving Hal)).

$04 \mathrm{Hal}$ : He:llo:, = ( (Mel, Mik shift gaze to arriving Hal))

05 Mel: =He: [y. Haley,

06 Mik: $\quad[+H E: y,=T h e r e$ she $i: s$. +figure $4 \mathrm{C}$

During Mike's utterance at line 2 (*Figure 4b), Ann shifts her gaze up toward the arriving newcomer Haley - an apparent initial sighting (Pillet-Shore 2018a) that directly precedes line 3 , and occasions her coparticipants to suddenly shift their gaze and joint attention to follow Ann's gaze to her selected, publicly perceivable referent (Figure 4c). It is plausible that Ann's "noticing" Haley's arrival, because she visibly appears to have just spotted an other-regarding referent, and audibly uses discovery prosody (cf. Goodwin 1979). At the same time, it is also plausible that Ann's "announcing" Haley's arrival, since she does not display a change-of-state in knowledge (Heritage 1984:286-87) or use a reaction token (Wilkinson and Kitzinger 2006), and she uses a third-person reference form to refer to the arriver, addressing her utterance to already-present and situated others.

While Excerpts 3 and 4 illustrate why this article does not use the vernacular metalinguistic terms noticing and announcing, what is clear from these excerpts - and all of my cases - is that this article's target action registers the referent, causing other participants to observably shift their sensory attention to it. Thus, this article uses the term registering to name the basic underlying social action for what it is apparently designed to do - to call joint attention to and achieve intersubjectivity over a selected publicly perceivable referent (rather than varying the name of the action depending upon what the referent is, or which participant does it).

Like Schegloff (2007), this article analyzes people registering referents affiliated to or identified with (at least) one of the participants, which I will call owned referents. ${ }^{7}$ This is distinctive from most other extant work, which predominantly examines unowned referents (for review, see Keevallik 2018). At the same time, this article fills a gap in Schegloff's work. When discussing "occasions on which someone has a new article of clothing, a new hairstyle, a new object in, or arrangement of, living quarters, etc., which is not registered by an interactional co-participant," Schegloff admitted he had "no taped instances" "at hand" (Schegloff 2007:86), noting that his comments were meant "to stimulate" subsequent "inquiry" (Schegloff 2007:88). But no study has yet investigated or demonstrated Schegloff's (2007:82) aforementioned claim about a possible preference organization (Pillet-Shore 2017) operative during registering sequences. This article fills this gap. 
After describing the data and method for this research, this article provides the first detailed empirical investigation of naturally occurring video-recorded sequences of copresent openings in which participants register owned referents. Focusing on sequence-initial actions, analysis demonstrates a systematic structural preference organization which observably guides when and how people initiate registering sequences sensitive to ownership of, and displayed stance toward, the target referent. This preference organization is evidenced across four subsections showing four key findings: (1) nonowners produce registering "yours" actions early and straightforwardly when displaying a clear positive stance toward the target referent, treating it as praisable; (2) owners produce registering "mine" actions early and straightforwardly when displaying a clear negative stance toward the target referent, treating it as criticizable; (3) owners delay their registering utterances, and design them to be neutral/nonvalenced, when targeting praisable referents; and (4) when nonowners design their registering utterances to be neutral/nonvalenced - delaying/withholding a stance-display - owners of the target referent regularly account for it, treating it as criticizable. This article's "Findings" section concludes with a deviant case analysis in which a participant produces a sequence-initial registering action in a way that apparently departs from other collected cases - an exceptional case that still shows evidence of participants' orientation to the normativity of this preference organization.

\section{DATA AND METHOD}

This study is part of a larger project in which I am examining how people open face-to-face interaction as newcomers arrive to a variety of residential and institutional settings (Pillet-Shore 2008, 2010, 2018a). I collected a data corpus involving over 435 residential encounters (e.g., friends, family, roommates coming home or coming over) and 96 workplace encounters (e.g., in schools, break rooms, restaurants, salons, gyms) with the informed consent of participants, and I anonymized all participant identifiers. My analysis of over 107 hours of naturally occurring video-recorded data yielded 542 copresent openings between English-speaking persons (on the west and east coasts of the United States) coming together to socialize and/or do work. Using the methods of conversation analysis (CA), I examined all registering sequences that occur in my corpus. I developed the details of my analysis for this article by closely examining 75 registering sequences occurring within the first 60-seconds of a participant's arrival. ${ }^{8}$ Transcripts follow CA conventions (using the system developed by Gail Jefferson) and, when IRB-permitted, include video frame figures showing key visible conduct.

\section{FINDINGS}

\section{Selecting How, What, and When to Register}

Registering is one way of making reference in interaction. As with other referential actions (cf. Enfield 2013), registering involves selection of what to register from 
among a vast number of perceivable, registerable stimuli; how to register from among a variety of different possible multi-modal (linguistic and embodied) methods; and when to register.

Regarding how to register, sequence-initial registering actions can be done through various design formats. For example, participants can design their registering utterances with or without evidential verbs (Chafe and Nichols 1986), as positive or negative observations (cf. Schegloff 1988), with or without reaction tokens (cf. Wilkinson and Kitzinger 2006), as primarily lexicalized or embodied (e.g., directed gaze + laughter/object showing), with declarative or interrogative grammar, and with or without explicating a positive $(+)$ or negative(-) stance toward the referent (see analysis of Excerpts 5-9 and 12-15 below). And using multiple modalities, participants can register in a way that displays a clear (positive, humorous, negative) stance toward the target referent, including positive(+) or negative(-) lexical descriptors and assessments (e.g., [+] "so cute" in Excerpts 2 and 5; [-] "Ew" and "Gross" in Excerpt 16), and audiovisual embodied resources (e.g., enacting a positive stance by incorporating "large" prosodic features - such as sound lengthening, smiling, and higher pitch - which Pillet-Shore 2012:383, 387] shows to audibly and visibly connote approval and praise).

Regarding what to register: people can register referents that are either owned or unowned. An unowned referent is not affiliated to any of the participants - it's an impersonal referent for which no participant is regarded as responsible (e.g., the weather). ${ }^{9}$ But as mentioned earlier, this article analyzes people registering owned referents - referents for which a participant is regarded as responsible. In naturally occurring encounters where participants orient to the setting as belonging to someone, me and mine are mingled (Lancaster and Foddy 1988). ${ }^{10}$ Thus, this section examines cases of people calling joint attention to publicly perceivable manifestations of the self, including not only how participants look (including hairstyle, clothing), smell, and sound, but also cases of people registering participants' self-extensions, like living/working/traveling quarters (e.g., how a person's residence, office, or car looks and smells), chosen or prepared offerings to fellow participants (e.g., gifts, foods), and other beings for whom one is regarded as responsible (e.g., how pets or young children look).

Regarding when to register: Broadly, people can register during different phases of interaction, including openings, closings, and in between (at places of possible sequence completion, including as a way of resolving a lapse in conversation; Hoey 2018). This section focuses on registering during openings, since this constitutes the majority of cases in my data set. ${ }^{11}$ More specifically, this section demonstrates that people time and design their sequence-initial registering actions in a systematic way constituting a structural preference organization - regular properties of turn and sequence construction through which participants manage courses of action that either promote or undermine social solidarity (Heritage 1984; Pillet-Shore 2017; Schegloff 2007). 
TABLE 1. Preference Organization When Registering an Owned Publicly Perceivable Referent

\begin{tabular}{lll}
\hline & DISPLAYING (+)STANCE: PRAISING & DISPLAYING (-)STANCE: CRITICIZING \\
\hline REGISTERING “YOURS" & $\begin{array}{l}\text { preferred } \\
\text { dispreferred }\end{array}$ & $\begin{array}{l}\text { dispreferred } \\
\text { REGISTERING “MINE" }\end{array}$ \\
\hline
\end{tabular}

\section{When to Register an Owned Referent:}

A Structural Preference Organization

Choosing to register an owned referent observably puts "face" (participants' interdependent, public images of self; Brown and Levinson 1987; Goffman 1967), "affiliation" (participants' continually updated displays of being "with" or "against" one another; Sidnell 2010), and thus the relationship of involved participants on the line. Empirically examining the theoretical notions of face-preservation and face-threat, CA work on "preference organization" elucidates how people systematically time and design their actions when there are alternative relevant actions possible (Heritage 1984; Pillet-Shore 2017; Schegloff 2007). This section demonstrates that sequence-initial registering actions can be done along a preference continuum, either: (i) sooner, with "preferred" design - close to initial perceptual exposure (Schegloff 2007:86) and at the earliest moment in the interaction when that registering action may be initially relevantly performed (cf. Pillet-Shore 2018a) - and straightforwardly (without mitigation, qualification, account, uncertainty); or (ii) later, with "dispreferred" design - delayed relative to points in the interaction when that registering action might otherwise have been initially relevantly performed (Pillet-Shore 2017; cf. Robinson and Bolden 2010:503).

The ensuing analysis shows that participants produce and understand sequenceinitial registering actions guided by the structural preference organization outlined in Table 1, which is sensitive to ownership ("yours," "mine") of, and displayed stance (e.g., positive[+], negative[-]) toward, the target referent. ${ }^{12}$ Each of the next four subsections demonstrates one cell in Table 1.

\section{Registering "Yours" and Displaying a (+)Stance}

Participants design registering "yours" actions as preferred when displaying a clear positive stance toward the target referent, treating it as praisable. In other words, nonowners regularly register referents straightforwardly and at the earliest moment in the interaction when that registering action may be initially relevantly performed as a way of enacting a positive stance toward that referent. This preference is observable when nonowners register a target referent on their recipient's body or in their recipient's personal territory.

We can see this preferred design in Excerpt 5 as Alec is entering his friend Linda's apartment. While still at the door's threshold (Figure 5a), Alec does a registering 
"yours" action about a referent (on Linda's shirt) toward which he displays a positive stance at line 4:
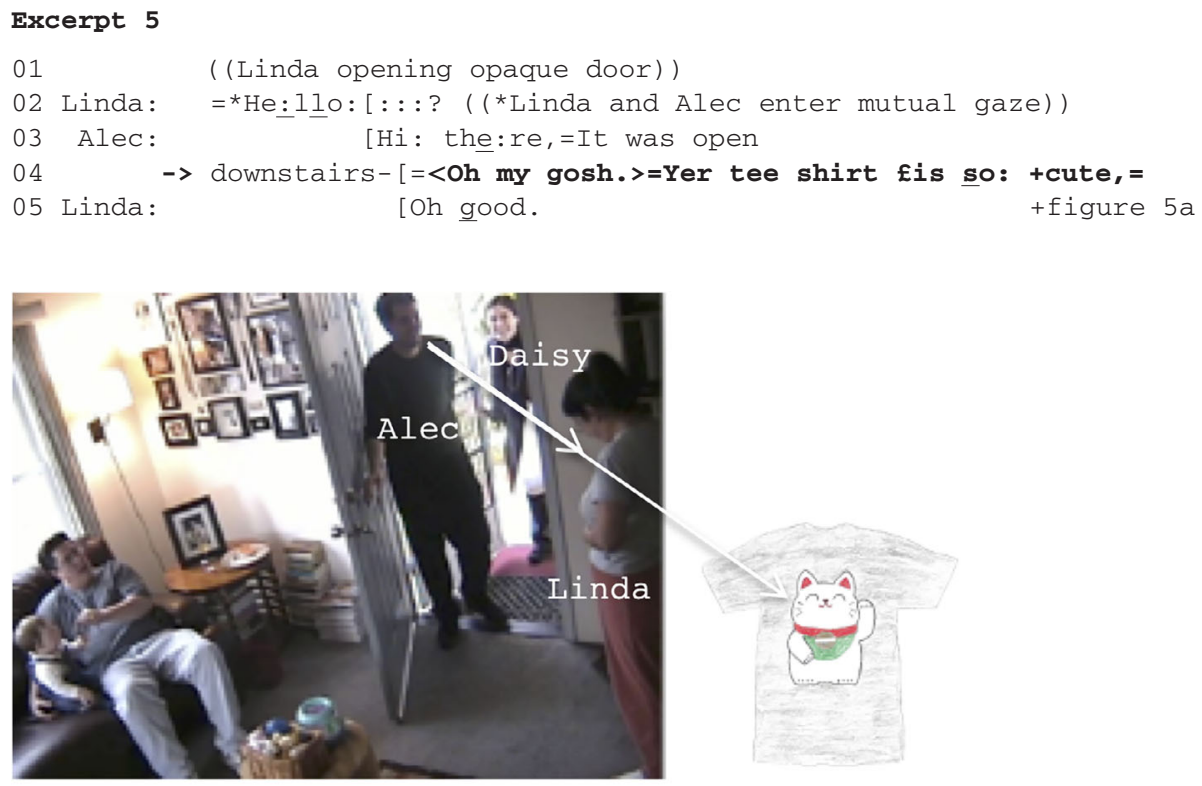

Figure 5 a

Figure $5 b$ Alec's referent

06 Daisy:

07 Linda:

$=£ I$ know $=\left[I\right.$ said that thuh last time I saw th\#et $\dot{i}^{-=}$

[Oh my lucky kitty? ((patting her shirt))

Just after greeting Linda and accounting for how he got through the locked gate downstairs (lines 2-4), Alec registers his visual perception of Linda's T-shirt, which features a maneki-neko (lucky kitty) graphic (Figure 5b). Alec indexes his realization of the referent through his "<Oh my gosh.>" reaction token (Wilkinson and Kitzinger 2006), rushing to explicate his target referent ("=Yer tee shirt") and then display a clear positive stance toward it by smiling as he gazes at it and delivers his praising assessment (Pomerantz 1984) of it as "so: cute." Alec uses his registering as a vehicle for complimenting Linda as the owner of the referent (Pillet-Shore 2015a). As Alec says the positive descriptor "cute," Linda gazes down (Figure 5a) to her own chest, subsequently patting the graphic on her shirt as she delivers her utterance at line 7. Excerpt 5 thus shows Alec designing his registering yours action as preferred, timing it to start at the earliest relevant moment in the emergent encounter (Pillet-Shore 2018a) and as close as possible to his apparent initial perceptual exposure to the referent (Schegloff 2007:86). Furthermore, Alec designs his utterance straightforwardly - without mitigation, qualification, account, or uncertainty.

This preferred design is also exemplified in Excerpts 1 and 2, which both show participants doing a registering "yours" action while displaying a positive stance: in Excerpt 1 Jill assesses her target referent with the positive descriptor "so go:od"; 
and in Excerpt 2 Sally displays a clear positive stance toward her target referent using multiple modalities, producing her sequence-initial registering utterance with "large" prosodic features (e.g., smiling, interpolated laughter, sound lengthening, and higher pitch; Pillet-Shore 2012) and including the positive descriptor "s(h)o: $\mathrm{c}(\mathrm{h}) \underline{\mathrm{u}}(\mathrm{h}):: \mathrm{t}(\mathrm{h})$ e." Excerpts 1 and 2 also show participants timing their registering actions to start at the earliest relevant moment in the emergent encounter - while still at or near the door's threshold and just after greetings - and very close to initial perceptual exposure. Furthermore, Excerpts 1, 2 and 5 show nonowners producing their sequence-initial registering utterances with preferred design features, delivering them straightforwardly. And in each case, the nonowner uses the registering action as a vehicle for achieving a particular social-relational purpose: complimenting the owner of the referent to enact and maintain incumbency in a more intimate relationship category (Pomerantz and Mandelbaum 2005), both achieving and renewing the close, affiliative character of that relationship by demonstrating other-attentiveness and other-involvement during the opening phase of their encounter (Pillet-Shore 2008, 2018b).

We can also see this preferred design in Excerpt 6, which is distinctive (from Excerpts 1,2, and 5) in showing a nonowner delivering a registering utterance composed of multiple turn-construction units (TCUs). In Excerpt 6, arriving guest Jess is entering the apartment of three peer-friends when she does a registering "yours" action, audibly pointing to her perception of Bri's change in hairstyle since the last time they saw one another. About 1-second after she first gazes toward seated Bri (Figure 6a), Jess does a double-take (Figure 6b) as she produces her sequence-initial registering utterance starting at line 4 :

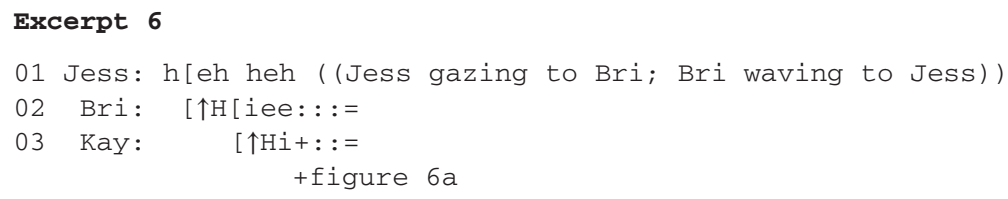

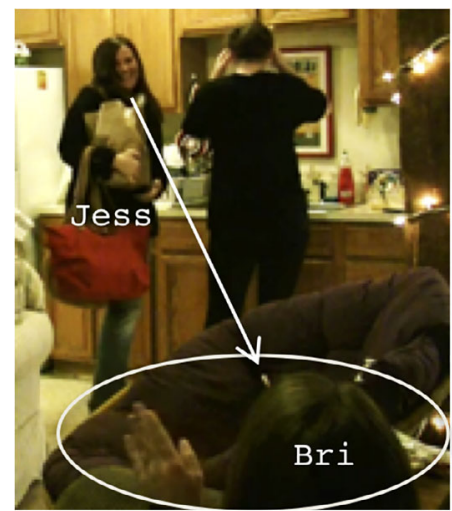

Figure $6 a$

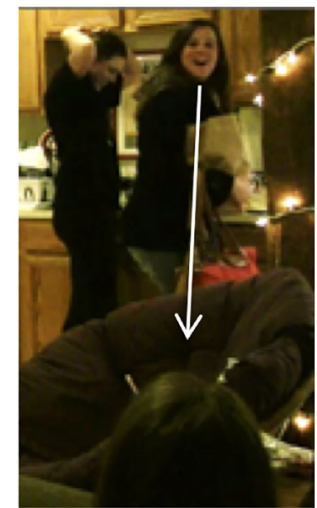

Figure $6 \mathrm{~b}$ 


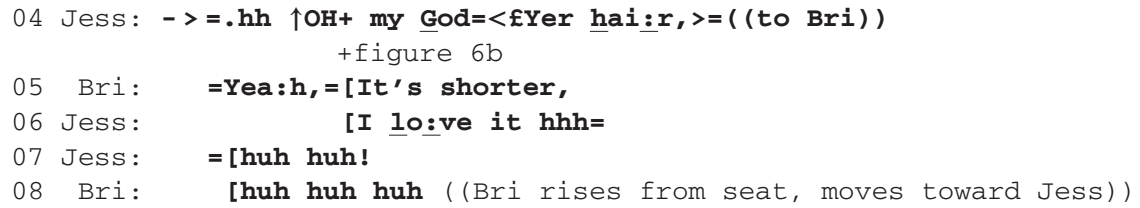

After producing a reaction token ("OH my God"), Jess registers the target referent ("<Yer hai:r,>”) in a lexically neutral/nonvalenced way at line 4 (naming the referent "<Yer hai:r, >" without explicating a $+/-$ stance toward it). Yet Jess embodies a positive stance toward her target referent through her audible and visible smiling and use of a "large" intonation contour (gliding from a high onset pitch to a lower pitch through all intermediate pitch values), a prosody connoting approval and praise (Pillet-Shore 2012). Then at line 6 Jess explicitly articulates her positive stance toward the target referent ("I lo:ve it").

Excerpts 7-9 also show nonowners delivering a multi-TCU registering utterance in which they first register the target referent in a lexically neutral/nonvalenced way (bolded), and then rush-through the next transition-relevance place (TRP) to explicitly articulate a positive stance toward the target referent:

\section{Excerpt 7}

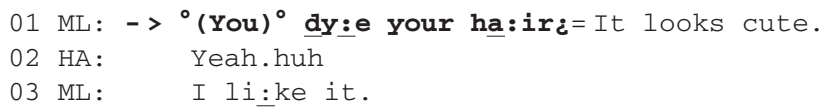

\section{Excerpt 8}

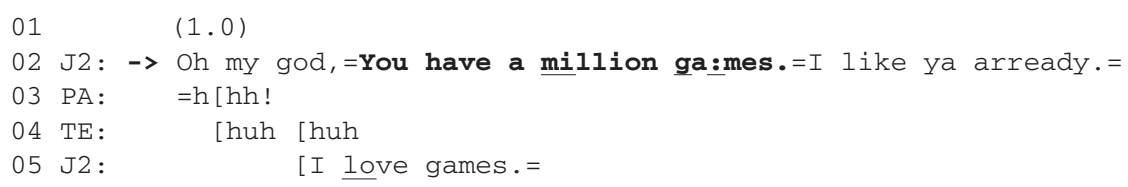

Thus Excerpts 6-9 show that, and how speakers can register a referent without explicating a clear (lexicalized) +/- stance toward it (for further discussion of this observation, see Excerpts 12-13, and Excerpts 14-15); and that each nonowner rushes to immediately append an explicit articulation of a positive stance toward the target referent. Furthermore, this entire subsection shows that a nonowner of a target referent can initiate a registering sequence as a vehicle for complimenting a fellow participant. 
When people open an interaction, they (re)constitute their social relationship (Pillet-Shore 2008, 2012, 2018a:215, Pillet-Shore 2018b; Schegloff 1986). And one important activity associated with incumbency in more intimate relationships (Pomerantz and Mandelbaum 2005) is demonstrating that one is monitoring for changes in one's recipient, relying on their shared history. Excerpts 2, 6, 7, and 9 show participants doing a registering "yours" action to show that they have detected a change in their recipient since their last encounter, thereby actively displaying other-attentiveness and doing "being in a closer relationship."13

\section{Registering "Mine" and Displaying a (-)Stance}

Participants design registering "mine" actions as preferred when displaying a clear negative stance toward the target referent, treating it as criticizable (Pillet-Shore 2015 b, 2016). In other words, owners regularly register referents straightforwardly and at the earliest moment in the interaction when that registering action may be initially relevantly performed as a way of enacting a negative stance toward that referent. This preference is observable when owners register a target referent on or about their own bodies or in their own personal territories - a referent that, though not being newly encountered by that speaker/owner, is newly perceptible to coparticipants. ${ }^{14}$

We can see this preferred design in Excerpt 10. Shortly after arriving to her friends' apartment, Hailey $(\mathrm{H})$, who is wearing shorts, registers a referent on her own body, toward which she displays a negative, humorous stance at line 9-11:

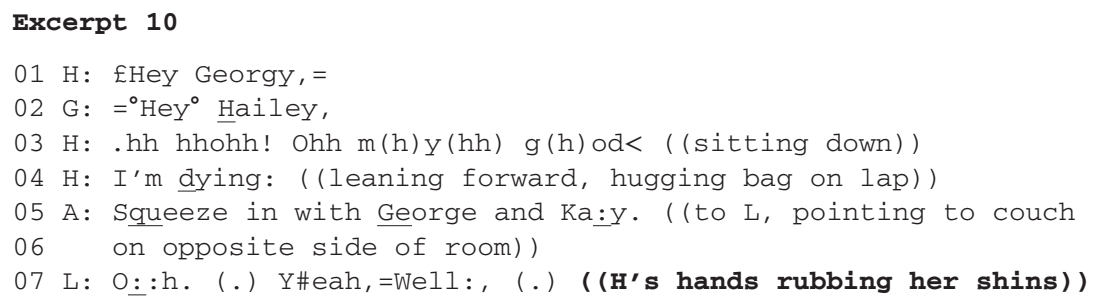

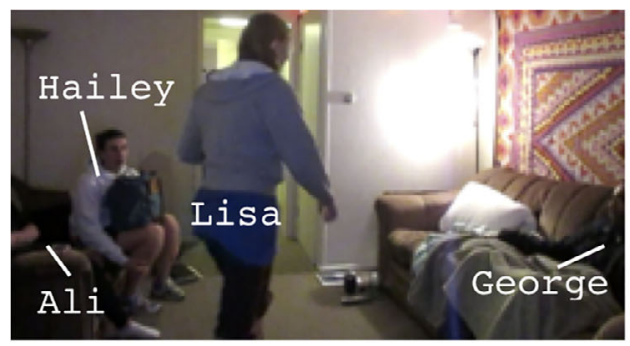

Figure 10a

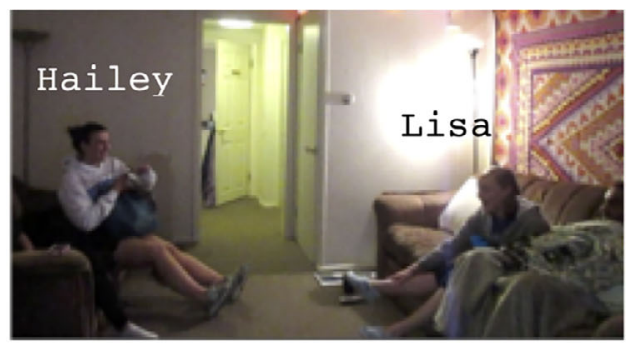

Figure 10b

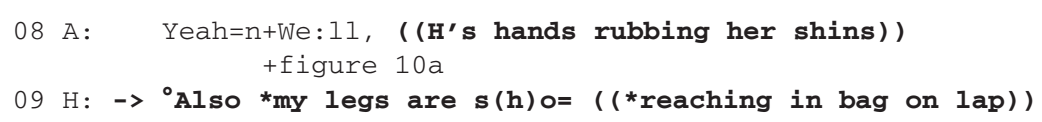




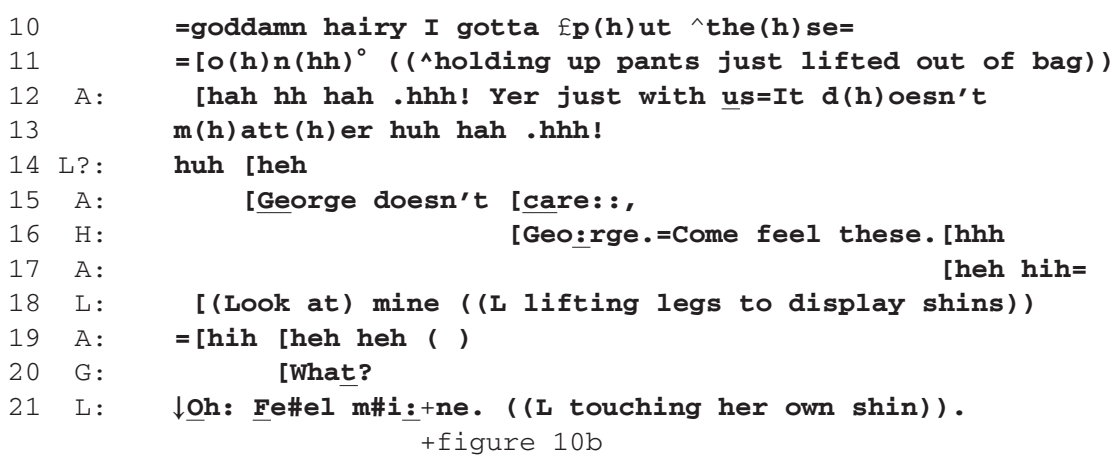

During the utterances at line 7-8, Hailey touches her own legs (Figure 10a), the apparent moment of her locally initial perceptual exposure to the (personally palpable) target referent (cf. Leichty 1975). Then, starting at line 9 Hailey calls her coparticipants' attention to her legs as being "s(h)o goddamn hairy," a registering that also does humorous self-criticizing/self-deprecating by using sotto voce delivery (Lerner 2013:96; treating this as an embarrassing matter; cf. Scheff 2005), audible smiling, interpolated laughter, and the negatively valenced impropriety "goddamn" (cf. Jefferson et al. 1987:160) which displays her frustration toward the referent. She times her delivery of this utterance as close as possible (given others' talk) to her apparent perception of feeling her "hairy" legs, and produces this utterance with preferred design, delivering it straightforwardly (without mitigation). Hailey thus preemptively registers a visible, and possibly palpable referent on her body that could have been registered by others, and uses infiltrating laughter to invite them to laugh with her, transforming a potential for criticism-by-other into an interactional opportunity for affiliation around a self-criticism (Pillet-Shore 2006). Moreover, Excerpt 10 (like Excerpt 2) shows how Hailey's action of registering a possibly visible and palpable referent occasions a joint multi-sensorial experience: while no one else touches Hailey's legs, at line 16 Hailey mock invites George (the lone man in the room) to "Come feel these," and Lisa responds (at lines 18 and 21) by displaying and touching her own shin (Figure 10b), thereby affiliating with Hailey and accepting her invitation into intimacy (cf. Jefferson et al. 1987) by claiming to also have hairy legs. Through this sequence, the participants talk and act (particularly at lines 9-11,12-13,21) in a way that is "recognizably bound" (Pomerantz and Mandelbaum 2005:153) with a close relationship category.

Excerpt 11 also exemplifies this preferred registering "mine" design. Emma's welcoming her Dad into her new single-occupant apartment after recently relocating from a smaller, run-down apartment. After invoking the reason for their encounter (Dad seeing her new residence for the first time) at line 8 by registering the entire space (and Dad positively assesses it at line 11), Emma starts an utterance comparing this place to the last, but then self-repairs at line 13 to register a visible, potentially criticizable referent: 


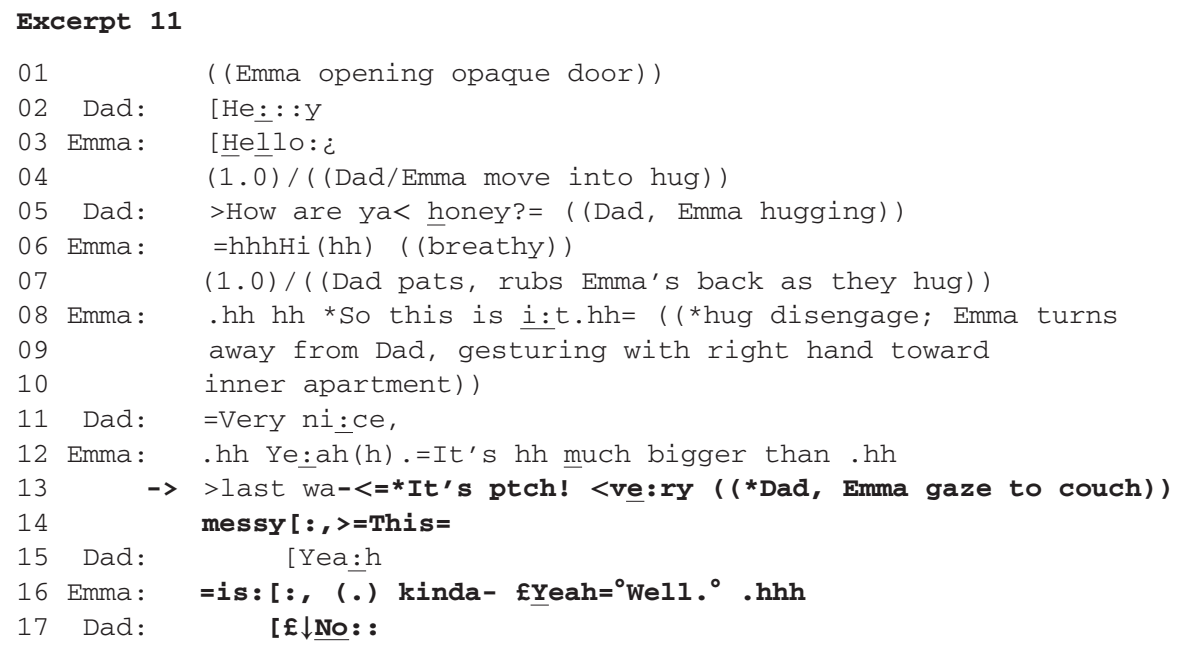

Emma displays a negative stance toward her target referent by prosodically producing her utterance at lines 13-14 as a concession (cf. Barth-Weingarten 2003), registering her apartment's appearance using the negative descriptor " $<$ ve:ry messy:,> - a criticizable referent, particularly by a parent (Dad) to an adult child (Emma). Emma times her registering to coincide with Dad's initial gaze toward her visibly untidy couch, apparently using it not only to self-deprecate but also - and more importantly - to preempt her Dad from possibly registering this criticizable referent first (cf. Pillet-Shore 2015c), thereby explicitly acknowledging as valid, and even agreeing with, her Dad's presumed critical point of view. And Emma produces this registering utterance with preferred design features, delivering it straightforwardly. Through their actions at lines 13-17, Emma and Dad tacitly collaborate to produce a registering sequence in which a potential for criticism-by-other becomes an opportunity for affiliation around a self-criticism (cf. Pillet-Shore 2016), achieving shared, concurrent smiling (lines 16-17) as they re-constitute their intimate social relationship (as close family members, and as father-adult daughter).

This section thus shows that an owner of a criticizable referent can initiate a registering sequence as a vehicle for both self-deprecating and preempting criticism from a fellow participant.

\section{Registering "Mine" and Displaying a Neutral Stance: (+)Stance Implicative}

When owners of a praisable referent initiate a registering sequence, they observably delay this action relative to points in the interaction when they might otherwise have initially relevantly performed it (Pillet-Shore 2017; cf. Robinson and Bolden 2010:503), thereby treating this action as dispreferred. Furthermore, they routinely design their sequence-initial registering utterances so they are specifically neutral/nonvalenced, thus allowing a nonowner to be first to articulate a (positive) stance toward the target referent. 
These dispreferred design features are exemplified in Excerpt 12. After waking up on Saturday morning, 12-year-old Layla enters her living room (at line 3) to find her neighbor and nanny Addison playing a board game with her younger sister Sue. Layla's had a hair cut in the week since she has last seen Addison. As Layla first becomes visible (Figure 12a), she runs both of her hands through her hair, displaying its freshly cut ends. After briefly gazing up at Layla to greet her at line 4, Addison returns her gaze down to the game. About 44-seconds later, after Layla's sat down on the floor to watch the others play, she once again touches her hair at lines 12 and 13 as she addresses her talk at line 14 to Addison. But it's not until line 27 that Layla explicitly registers the change to her hair, exactly 60-seconds after she has established copresence with Addison:
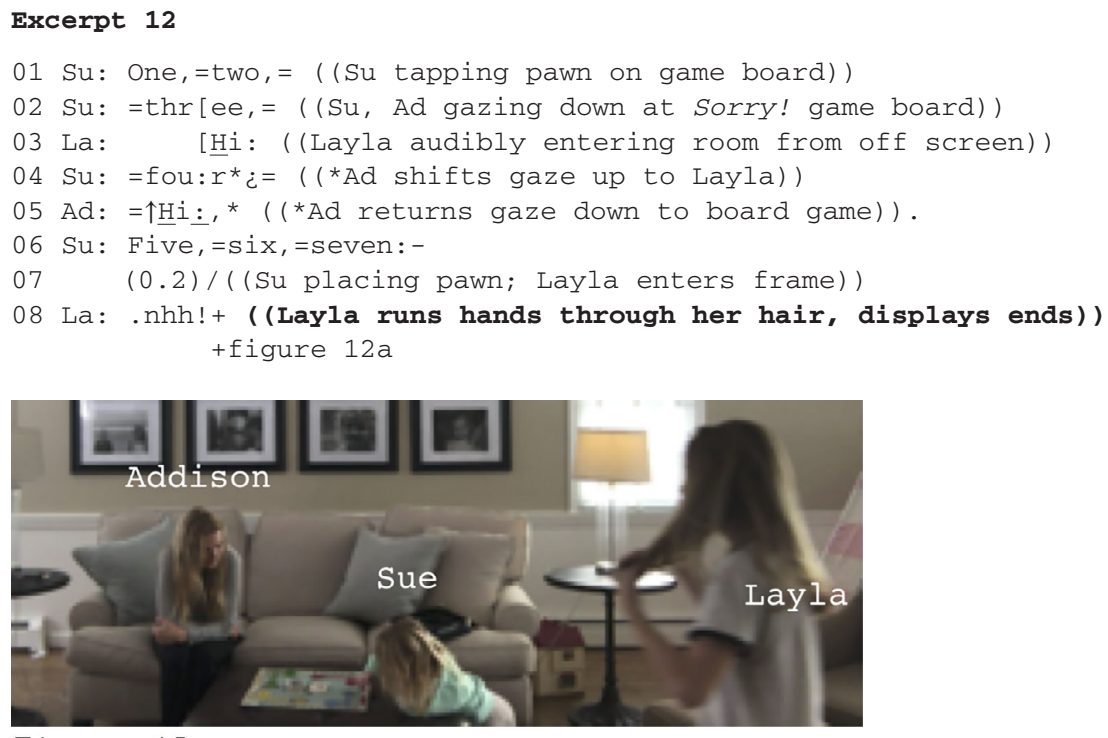

Figure 12a

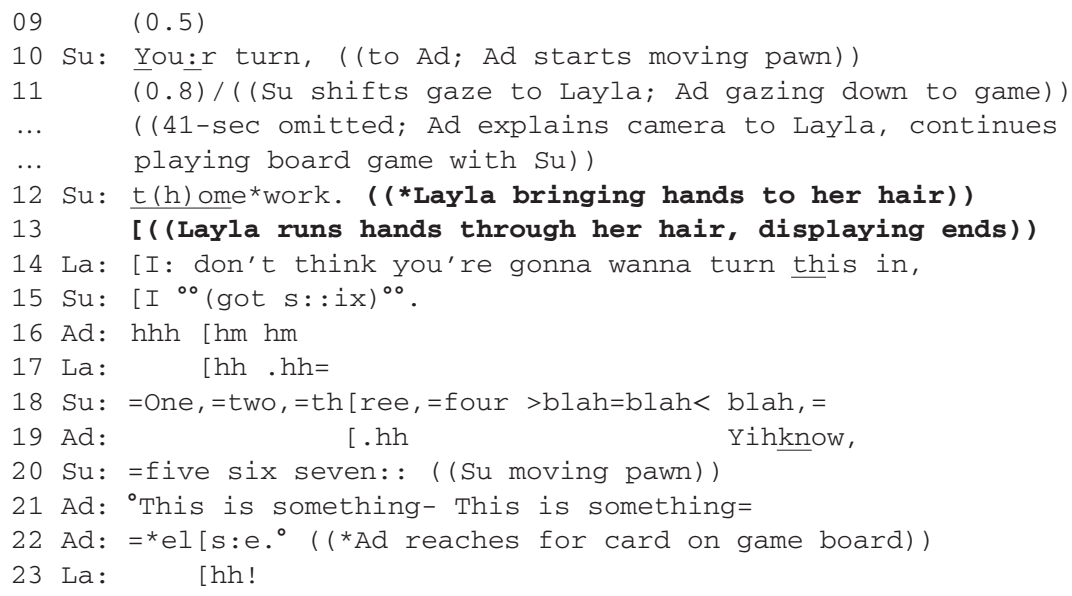




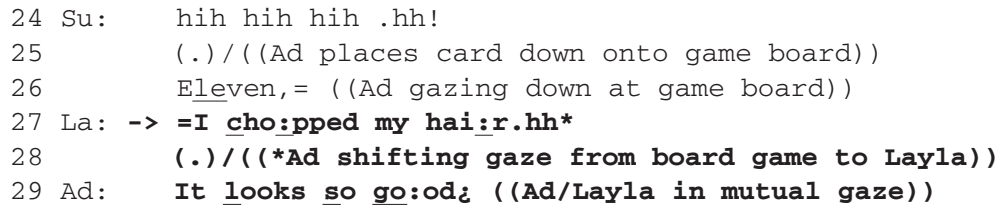

Layla observably delays her registering utterance relative to Addison's initial perceptual exposure (as early as line 4; Schegloff 2007:86) and relative to earlier points in the opening phase when Addison might have relevantly registered her hair cut. During this time, Layla displays the freshly cut ends of her hair twice (lines 8, 12-13), apparently to enhance the opportunity for Addison to do the preferred alternative (of registering "yours" while displaying a [+]stance). Moreover, in the way that Layla designs her sequence-initial registering utterance at line 27, she specifically avoids articulating a valenced-stance toward her own hair, allowing her recipient Addison to be first to articulate a positive stance toward the target referent (through her positive descriptor "so go:od") at line 29. ${ }^{15}$

We can see a similar pattern in Excerpt 13. Dave has arrived to his neighbor Kiki's house for a holiday party 40-seconds before line 1. After Kiki's small dog Bailey (a miniature poodle) puts his front paws up on Dave's side (line 1), Dave attends to the dog, lifting and hugging him as he addresses him by his nickname "Bay leaf" (line 2):

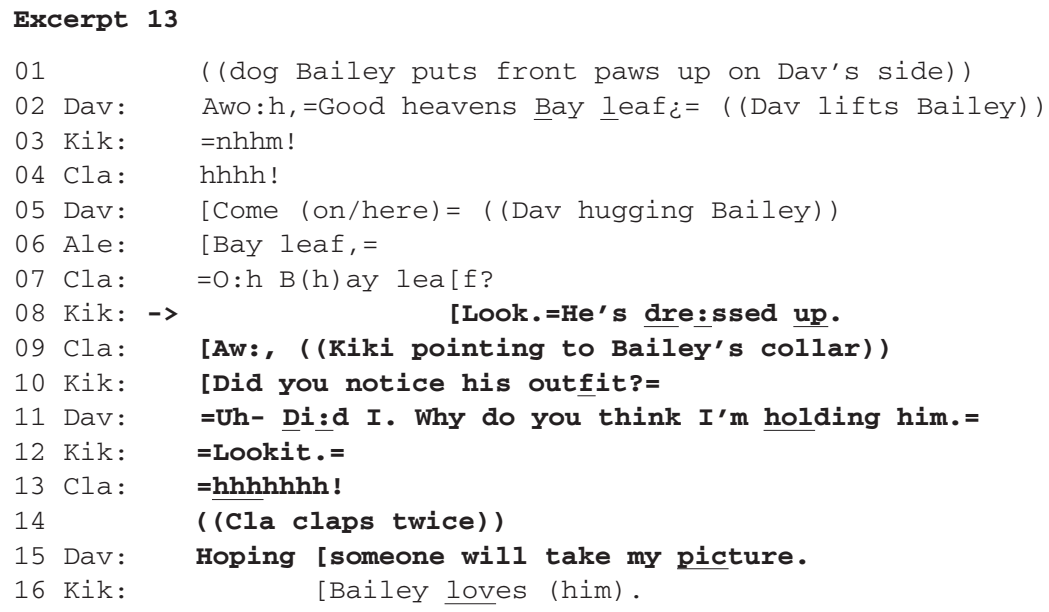

Though the dog's action at line 1 initially attracts Dave's attention, Kiki's actions starting at line 8 register a more refined referent: how she has adorned her dog. Kiki's utterance at line 8 is a directive ("Look") followed by a formulation of the $\operatorname{dog}(" \mathrm{He}$ ") as "dre:ssed up" which, though connoting the wearing of a costume and/or formal attire, stops short of including a descriptor or assessment. Thus 
Kiki designs her registering utterances so they are specifically neutral/nonvalenced (describing without assessing) and omit explicit reference to herself as the person responsible for adorning the dog (she does not say, e.g., "Look how I dressed him"). At line 10, Kiki also formulates the action she's now asking Dave to do as one that he could (and perhaps should) have already done (at least cognitively, if not socially). She thereby registers his failure to register the dog's "outfit" (cf. Schegloff 2007:86). ${ }^{16}$ By line 8, Kiki has allowed 46-seconds to elapse since Dave's arrival, time during which Dave has attended to her dog several times (and yet has not interactionally registered his outfit). Thus, Kiki observably delays her registering, evidence of her orientation to this action as relatively dispreferred. ${ }^{17}$

This section thus shows that, when an owner of a referent initiates a registering sequence with an utterance designed to be neutral/nonvalenced, participants are likely to infer that the owner is fishing for a recipient's positive stance-display toward that target referent.

\section{Registering "Yours" and Displaying a Neutral Stance: (-)Stance Implicative}

When nonowners of a criticizable referent initiate a registering sequence, they routinely design their sequence-initial registering utterances to be neutral/nonvalenced. Though we have already seen cases of speakers uncoupling their registering action TCU from their stance-displaying action TCU (Excerpts 6-9 showed nonowners first registering the target referent in a lexically nonvalenced way, and then rushing-through the next TRP to explicitly articulate a positive stance toward it), Excerpts 14-15 below show nonowners doing a neutral/nonvalenced registering TCU as a stand-alone action (choosing to not rush-through the next TRP to start a next TCU, and withholding/delaying a lexicalized stance-display). And in each case, the owner of the target referent treats it as criticizable, using their next turn to account for it.

In Excerpt 14, moments after arriving to her home and greeting her daughter's friend Elsa, Mom shifts her attention to greeting her college-aged daughter Kelly, who's visiting home before leaving with Elsa for a Spring Break trip to Florida. As Mom walks toward Kelly, she lowers her gaze from her daughter's face to her chest (Figure 14a), embodying a registering action as she delivers a quiet neutral/nonvalenced utterance (line 2) that registers her entire daughter as referent. Over 1-second elapses between the end of Mom's utterance at line 2 and the start of her utterance at line 6 , time during which she does not start a next TCU to lexicalize a stance-display toward her target referent:

Excerpt 14

01 (0.5)/((Mom approaches Kel, gazing to Kel's chest))

02 Mom: -> ${ }^{\circ}$ Look at +chyou: : ${ }^{\circ}$ ((Mom splays arms))

+ figure $14 a$ 


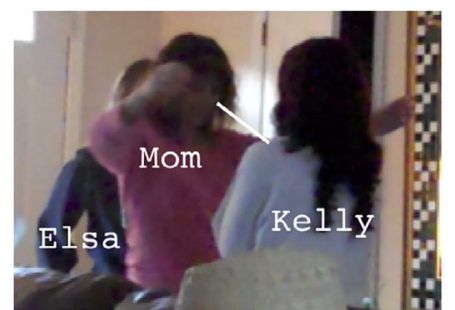

Figure 14a

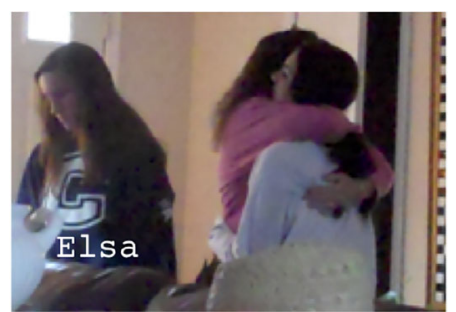

Figure 14b

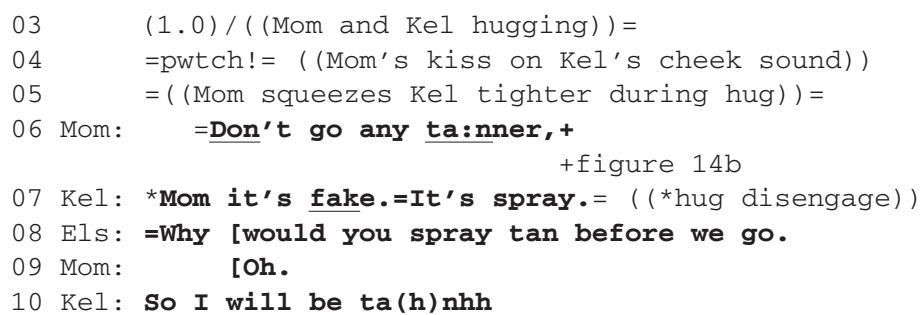

Through her utterance at line 6, Mom issues a directive that constitutes an implied registering and criticism of how tan Kelly's skin looks, thereby performing an action treated as appropriate given the rights and obligations of the mother-daughter relationship categories (Pomerantz and Mandelbaum 2005). This encounter occurs in late-winter in the Northeastern United States, and Mom's manifest concern is that her daughter looks (too) tan as a result of exposure to ultraviolet (UV) rays from tanning salon lamps, which increase the risk of skin cancer. From the moment of initial perceptual exposure, Mom delays making this specific referent explicit, and she also avoids articulating a negative stance toward this referent, both of which show her orientation to her actions as dispreferred and face-threatening. And Kelly responds by providing an account (line 7) for the target referent (her skin color) which displays her orientation to, and aims to assuage, her Mom's implied concern ("It's spray" conveys that her tan is not from UV rays). At line 8, Elsa delivers a why-type interrogative (Robinson and Bolden 2010) that solicits further account from Kelly, thereby continuing a criticizing sequence.

Excerpt 15 further exemplifies this pattern. As Jane (J) arrives to her friends' apartment, her already-present and situated roommate and closest friend Alice (A) initiates a registering sequence at line 4 with a turn composed of a reaction token and an explication of her target referent, thereby registering Jane's all-gray outfit through a lexically neutral/nonvalenced utterance. Kate then echoes Alice's registering by defining it (line 5) in a nonvalenced way, and all participants smile and laugh, using their actions to tease and criticize Jane for her monochromatic clothing (cf. Haugh 2017), thereby enacting incumbency in a close peer friend relationship (Pomerantz and Mandelbaum 2005). 


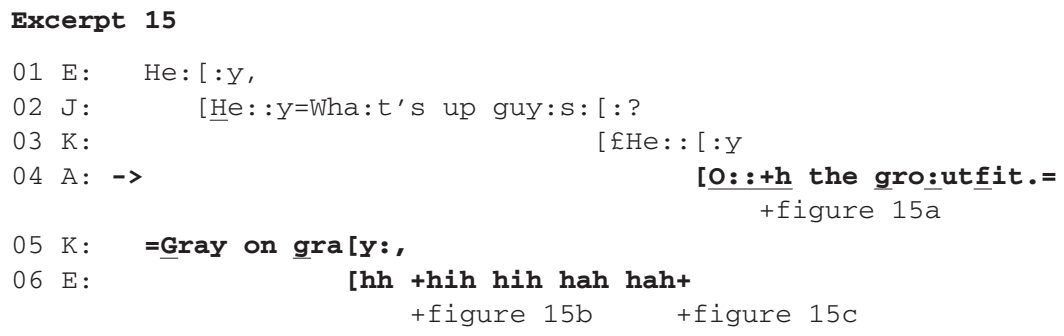

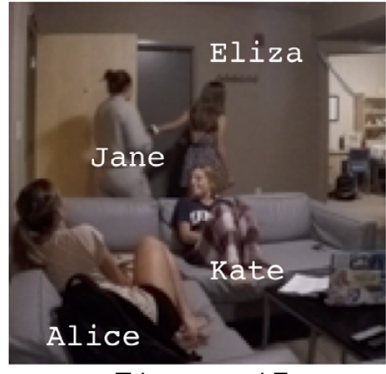

Figure 15a

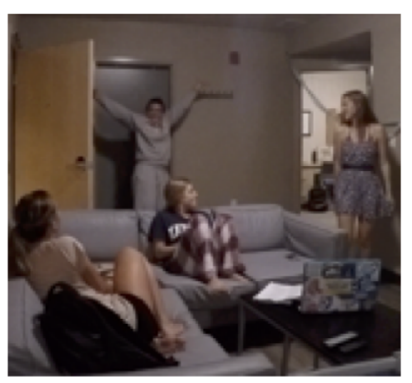

Figure $15 b$

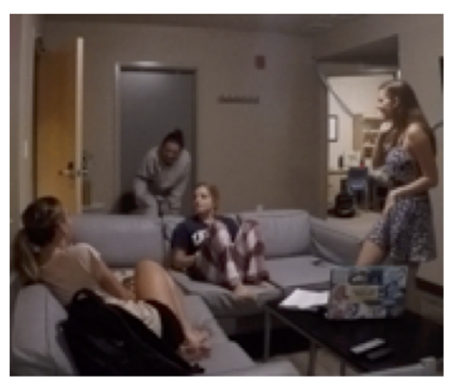

Figure 15:

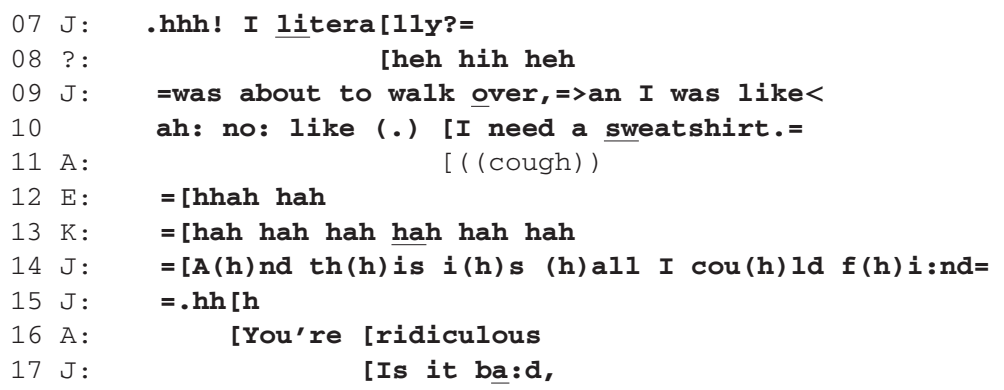

After Jane initially responds with a proud display gesture (Figure 15b) and laughter, she accounts for the target referent (lines 7, 9-10,14). By then asking "Is it ba:d," at line 17, Jane demonstrates her orientation to her interlocutors' neutral/nonvalenced registering actions as implying a negative, criticizing stance toward her outfit.

This section thus shows that when a nonowner of a referent initiates a registering sequence with an utterance designed to be neutral/nonvalenced - registering the referent without expressing a clear $+/$ - stance toward it - participants are likely to infer that the nonowner is implying and eliding a negative stance toward that referent and thereby criticizing its owner.

\section{Deviant Case Analysis}

While the foregoing analysis has shown that and how participants produce and understand sequence-initial registering actions consistent with the structural preference organization outlined in Table 1, Excerpt 16 offers an opportunity for a deviant 
case analysis. Shortly after entering his friends' apartment, Greg initiates a registering sequence starting at line 8 :
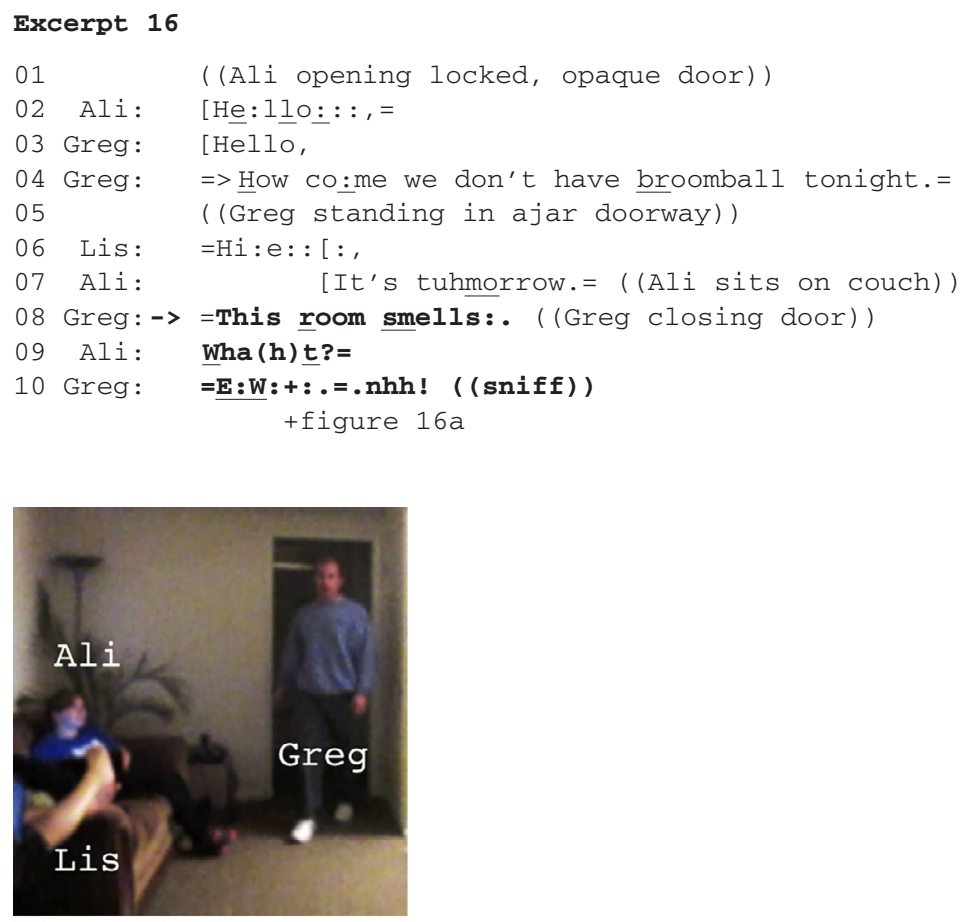

Figure 16a

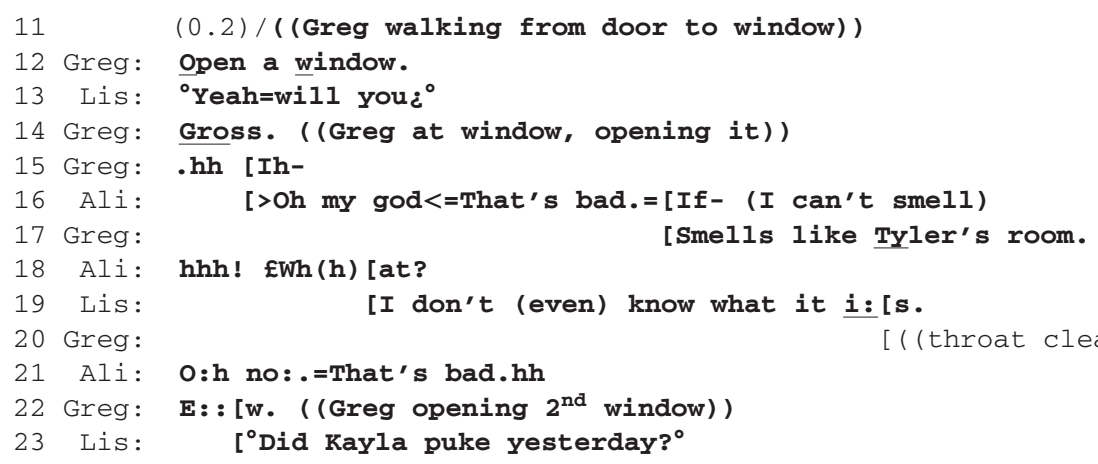

With his declarative, "This room smells:," Greg registers his sensorial experience of perceiving an olfactible referent. While he does not use a clear assessment (e.g., "smells bad" or "stinks"), his use of the verb "smells" idiomatically connotes an unpleasant odor - a criticizable and complainable referent (Pillet-Shore 2015b, 2016). Moreover, as an arriving visitor to his friends' residence, Greg is a nonowner of this referent. And yet, rather than designing his registering "yours" 
action as dispreferred (by delaying it, and/or producing it non-straightforwardly with mitigation, qualification, or uncertainty), he delivers it early (close to apparent initial perceptual exposure) and straightforwardly, in effect doing a face-threatening/dispreferred action with preferred design (Pillet-Shore 2017).

Resident Ali responds at line 9 with an "open" class repair initiator (Drew 1997), treating Greg's preceding action - which constituted an abrupt topic shift - as problematic, but leaves unclear if the problem is one of hearing, understanding, or affiliation. Based on coparticipants' next actions and Ali's similar utterance at line 18, however, it becomes clear that it's a problem of affiliation. At line 10, Greg displays a clear negative stance toward his target referent (through his "E:W:" - a dedicated negative stance-display that he renews through his utterances at lines 14 and 22), treating it as not only criticizable but also complainable (Pillet-Shore 2015b, 2016). By then audibly sniffing, moving toward the apartment's windows as he delivers the directive at line 12, and opening two windows (at lines 14 and 22), Greg moves to remedy the complainable smell.

Given the structural preference organization outlined in Table 1, how can we explain Greg's registering actions in Excerpt 16? First, olfactory fatigue (a case of sensory adaptation $)^{18}$ is apparently at work: the residents' subsequent talk (line 16-23 and beyond) reveals that after their prolonged exposure to this odor they are unable to detect it, thus precluding the possibility that they could preemptively register (or remedy) the smell. Greg's registering actions may thus be articulating a trouble relevant to his recipients, formulating it as a shared adversity/witnessing (cf. Sacks 1992 I:236-246). Second, the target referent in this case is communal: four college students share this apartment, thus creating a diffusion of responsibility around who owns the criticizable referent (see line 23). ${ }^{19}$ And third and perhaps most importantly, these participants orient to one another as incumbents in a very relaxed, close relationship: ethnographically, we know that Greg is a frequent visitor to this residence, a familiarity he embodies through his entitled (nondeferential) action of opening his friends' windows. Thus Excerpt 16 shows how people can use registering actions to display a high degree of social closeness and intimacy: when participants orient to one another as having an unguarded and highly familiar relationship - the strength of which they treat in situ as able to withstand the momentary strain posed by a face-threatening action - they may not only perform a dispreferred action, but may do so with relatively preferred design. Indeed, as suggested by Pillet-Shore (2017), this may be one of a larger class of activities permitted, but not necessarily expected, between persons who are incumbents of intimate relationships - a way of doing "being intimate" (cf. Pomerantz and Mandelbaum 2005) that transcends registering sequences to include many other social action sequences (e.g., how recipients of polar questions can perform dispreferred responding actions in the preferred design format; Pillet-Shore 2017:37). So it seems Excerpt 16 is an exception that still proves the rule. 


\section{CONCLUSIONS}

This article has provided the first detailed empirical investigation of naturally occurring video-recorded face-to-face openings during which participants do the action of registering - calling joint attention to a selected, publicly perceivable referent so others shift their sensory attention to it. Through this action, interactional coparticipants make the sensory social by invoking a present, personal perceptual experience so they may immediately share it. Complementing modern social psychology and symbolic interaction scholarship, this article shows how interactants use the action of registering not only to achieve "joint attention" (shared awareness of the same referent at the same time; e.g., Bruner 1995; Tomasello and Farrar 1986), but also to achieve "intersubjectivity" and "attunement" (Scheff 2005), sharing a common understanding of the meaning and value that they are attributing to that referent. Closely analyzing sequence-initial actions that register owned referents (for which a participant is regarded as responsible), this study has elucidated a systematic structural preference organization that observably guides when and how people initiate registering sequences sensitive to ownership of, and displayed stance toward, the target referent.

This article has shown evidence of this preference organization through four key findings. First, analysis revealed that nonowners register praisable referents early and straightforwardly (preferred design) - a key method for doing a sequence-initial complimenting action (cf. Pillet-Shore 2015a). Second, data demonstrated that owners register criticizable referents early and straightforwardly (preferred design) - a key method for doing a sequence-initial self-deprecating action that can work to preempt another's criticism/complaint (cf. Pillet-Shore 2015b, 2017). Third, this article showed that owners delay their registering utterances (dispreferred design), and design them to be neutral/nonvalenced, when targeting praisable referents - actions to which fellow participants are likely to orient as fishing for a another's positive stance-display toward the target referent. And fourth, this study demonstrated that, when nonowners design their registering utterances to be neutral/nonvalenced - delaying/withholding a stance-display (dispreferred design) - owners regularly account for the target referent; thus, participants orient to a nonowner's neutral/nonvalenced registering as implicitly criticizing the referent and its owner.

These findings connect to interactionist discussions of "intersubjectivity," which observe that we humans "spend much of our lives living in the minds of others," and "our self-feelings are dependent on other people" (Scheff 2005:156). This article has examined moments during copresent interaction when participants topicalize and manage not only how they and theirs look, smell, sound, and feel, but also deal with others' displayed stances toward and "judgments" of those sensory perceptions, which interactionist scholarship tells us "gives rise to real and intensely powerful emotions" (Scheff 2005:147). 
We've seen that people use registering an owned referent as a vehicle for doing other stance-implicative actions, including complimenting, self-deprecating to preempt a fellow participant's potential criticism, fishing for another's praise, or implicitly criticizing a fellow participant. Analysis has shown that and how participants use the timing of the registering vehicle to partially constitute (along with concomitant lexical, prosodic, and embodied stance-displays), and make recognizable, which other action they are doing through it. Courtesy of the complementarity built into the preference organization outlined in Table 1, people can tacitly collaborate to produce "preferred" registering sequences that support social solidarity. Through their choices to produce actions that either promote or undermine social solidarity during openings, interactants partially (re)constitute and enact their social relationships, calibrating the degree of intimacy or distance and "social connectedness" (Scheff 2005:151) between them.

By concluding with a deviant case analysis, this article showed that people can, of course, depart from the structural preference organization outlined in Table 1. But when they do, their actions are inference-rich and accountable, engendering fellow participants to wonder "Why that now?" (Schegloff 2007:2; Schegloff and Sacks 1973:299), which can lead to negative inferences and a threat to their bond (Scheff 2005:151). Indeed, this deviant case still showed evidence of participants' orientation to the normativity of this preference organization, further illuminating how choosing to register an owned referent puts involved participants' face, affiliation, and social relationship on the line.

The findings of this research contribute to several bodies of work, including interactionist and sensory studies exploring multi-sensorality in interaction (e.g., Leichty 1975; Mondada 2019) to describe how people make their sense perceptions relevant and accountable to fellow participants. Moreover, this article complements and extends CA work on preference organization (Heritage 1984; Pillet-Shore 2017; Schegloff 2007), particularly of sequence-initiating actions (for review, see Pillet-Shore 2017). This article also advances the social scientific literature on joint attention (e.g., Moore and Dunham 1995), the achievement of intersubjectivity (e.g., Heritage 1984:254-256; Scheff 2005), and the openings of interactions (Pillet-Shore 2018a). By registering owned referents during conversational openings, participants do not only move to solve the practical problem of topic initiation (what to talk about early in an emergent encounter); they also - and perhaps more importantly - move to achieve and renew the character of their social relationships.

\section{ACKNOWLEDGMENTS}

This article began in 2005 as a chapter written for my dissertation (Pillet-Shore 2008), and I've been collecting and analyzing additional cases of the focal phenomenon ever since. I presented versions of this analysis at the 2017 International Pragmatics Conference in Belfast, Northern Ireland, and the 2018 International Conference on Conversation Analysis in Loughborough, England. I am grateful to Manny Schegloff 
for discussing this project with me in its earliest stages. This article has benefitted from the helpful comments offered by the editors and reviewers of this special issue, Saul Albert, Lucas Seuren, Mick Smith, and members of the Tufts University Human Interaction Lab who gave me the opportunity to present some of this article's data to them in November 2018.

\section{NOTES}

1. Registering is not confined to face-to-face interaction. Among others, Drew and Chilton (2000) and Schegloff (2007) mention registering (or vernacularly, "noticing" - see the section entitled "Background") actions in their analyses of recorded telephone conversations.

2. People are more likely to register tasteable referents outside of the opening phase of interaction, often mid-encounter (e.g., while cooking, eating, drinking; see Højlund 2015; Vannini et al. 2010).

3. Data in this article also use an exclamation point "!" following an abruptly punctuated sound, an asterisk "*" to indicate onset of visible conduct described inside double parentheses " $((*))$ " and a plus "+" to denote the moment in the transcript that a video frame grab figure occurs.

4. Excerpt 10 is another exemplification of a registering sequence occasioning a joint multisensorial experience.

5. The New Iowa School of Symbolic Interaction (e.g., Miller et al. 1975; Miller 2011:343-44) also conducted laboratory studies to explore "the opening phase of social acts" and how "reciprocally acknowledged attention" is established.

6. Among these studies, Maynard and Zimmerman (1984) is distinctive in not analyzing naturally occurring recorded interactions, but rather examining recordings of college student dyads in a lab experiment, finding that participants initiated topics using what they termed "setting talk" - referring to an element of the immediate laboratory environment. I do not use the term "setting talk" because in my data set the action of registering does not necessitate talk; people can use directed gaze, a deictic gesture, and/or laughter to initiate registering; and registering is not limited to referents tethered to the setting - participants call attention to publicly perceivable features of the setting and participants in the same sequential and overall structural position.

7. Though worthy of study, a focus on how participants negotiate and display referent (non-)ownership during their interactions is beyond the scope of this article.

8. While most arrivals in my data set show participants entering from outside into an interior space, a few cases show arrivers entering a common room after waking from sleep in a nearby bedroom.

9. Excerpt A shows Willow registering an unowned referent at line 1:

Excerpt A

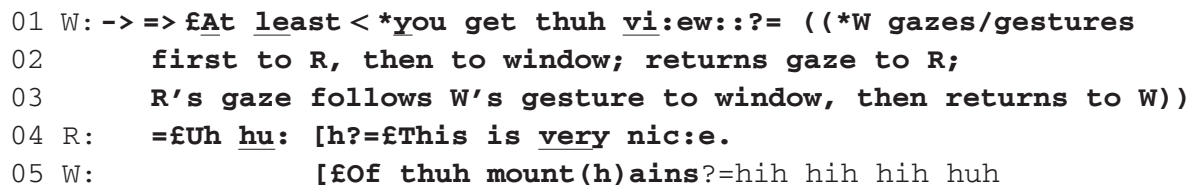

By registering the view through the window (which is related to the weather, and is treated as out of participants' accountable control) of the university's borrowed meeting room (it's not Willow's personal office), Willow registers an unowned referent (constituting recipient Robin as a beneficiary).

10. This article's findings empirically demonstrate several authors' claims that the self is distributed and heterogeneous. For example, an assertion made by James (1890, 291, as cited in Lancaster 
and Foddy 1988) highlights the difficulty in distinguishing between me and mine: "In its widest possible sense, a man's self is the sum total of all that he can call his, not only his body and his psychic powers, but his clothes and his house, his wife and children, his ancestors and friends, his reputation and works."

11. My data set includes non-opening cases of registering, analysis of which shows participants to produce and understand sequence-initial registering actions consistent with the structural preference organization outlined in Table 1.

12. Though it's possible to register in a lexically neutral/nonvalenced way (without explicating a clear +/- stance toward the target referent, e.g., "Look at you::"; "Oh wo: w.=Look at that."; "You sat in the barber's chair this weekend"), nonvalenced registering utterances are a regular part of dispreferred design, both when registering "mine" (see Excerpts 12-13) and when registering "yours" (see Excerpts 14-15).

13. This observation also applies to, and yields additional insights about, Excerpts 12 and 14 (and may also apply to Excerpts 13 and Note 17's Excerpt B).

14. Reconsidering Excerpt 3, Ryan's registering at line 7 may be a case of registering "ours" with preferred design, displaying either a neutral/nonvalenced stance, or a (-)stance (if participants orient to a bug on their residential ceiling as criticizable, implying a lack of cleanliness or posing a nuisance).

15. See also Excerpt 11-line 8 and Excerpt 13-line 8. I have found that this preference organization of registering an owned referent also applies outside of the opening phase of interaction, during "ongoing states of incipient talk" (Schegloff 2007; Schegloff and Sacks 1973).

16. Dave designs his response at line 11 to sound playfully indignant, treating it as obvious that he has not only "noticed," but is already responding to and acting upon that "noticing" by showing affection to the dog.

17. Excerpt B shows the very next guest to arrive to Kiki's house for this same holiday party. Tellingly, this arriver (Deanne) registers how Kiki's dog Bailey is adorned very early and straightforwardly, starting at line 5 while still at the door's threshold:

Excerpt B

01 ((knock knock knock))/((Dea at Kiki's ajar front door))

02 Kik: $\uparrow \underline{A}: \underline{:}$ H.

03 (0.5)/((dog Bailey runs to Dea at door))

04 Dea: Oh hi Bailey Hi $_{\text {: }}$ :ee. Hi:hih (you) hih hih=

$05->=$ Goodness that's so cute $\quad$ =Looket shyer ne:cklace.=

$06 \mathrm{Dea}: \quad$ heh heh heh He's so festive. ((gazing to Kiki))

So this next arriver does the more preferred registering "yours" while displaying a $(+)$ stance action (using positive descriptors/assessments and praising prosody) with preferred design (consistent with Excerpts 1,2 and 5-8).

18. Wikipedia, The Free Encyclopedia, "Olfactory fatigue," (retrieved June 20, 2017), https://en .wikipedia.org/wiki/Olfactory_fatigue.

19. Both Excerpts 3 and 16 show participants registering a target referent that is oriented to as shared or communal, which likely influences the preference organization of their actions; this merits further study.

\section{REFERENCES}

Albert, Saul and M. Sean Smith. 2018. "Noticings as Actions-in-Conversation." Presented at the 5th International Conference on Conversation Analysis, July 14, Loughborough, UK.

Barth-Weingarten, Dagmar. 2003. Concession in Spoken English: On the Realisation of a Discourse-Pragmatic Relation. Tubingen, Germany: Gunter Narr Verlag.

Bergmann, Jörg. 1990. "On the Local Sensitivity of Conversation.” Pp. 201-282 in The Dynamics of Dialogue, edited by I. Markova and K. Foppa. Hertfordshire: Harvester. 
Brown, Penelope and Stephen C. Levinson. 1987. Politeness: Some Universals in Language Usage. Cambridge: Cambridge University Press.

Bruner, Jerome. 1995. "From Joint Attention to the Meeting of Minds: An Introduction." in Forward in Joint Attention: Its Origins and Role in Development, edited by C. Moore and P. J. Dunham. Hillsdale, NJ: Lawrence Erlbaum Associates.

Carpenter, Malinda and Kristin Liebal. 2011. "Joint Attention, Communication, and Knowing Together in Infancy." Pp. 159-181 in Joint Attention: New Developments in Psychology, Philosophy of Mind, and Social Neuroscience, edited by A. Seemann. Cambridge, MA: MIT Press.

Chafe, Wallace L. and Johanna Nichols, eds. 1986. Evidentiality: The Linguistic Coding of Epistemology. Norwood, NJ: Ablex.

Drew, Paul. 1997. “'Open' Class Repair Initiators in Response to Sequential Sources of Troubles in Conversation." Journal of Pragmatics 28:69-101.

Drew, Paul and Kathy Chilton. 2000. "Calling Just to Keep in Touch: Regular and Habitualised Telephone Calls as an Environment for Small Talk." Pp. 137-162 in Small Talk, edited by J. Coupland. Harlow: Pearson Education.

Enfield, N. J. 2013. "Reference in Conversation." Pp. 433-454 in The Handbook of Conversation Analysis, edited by J. Sidnell and T. Stivers. Malden, MA: Blackwell Publishing Ltd.

Goffman, Erving. 1967. Interaction Ritual: Essays in Face to Face Behavior. Garden City, NY: Doubleday.

Goodwin, Charles. 1979. "The Interactive Construction of a Sentence in Natural Conversation." Pp. 97-121 in Everyday Language: Studies in Ethnomethodology, edited by G. Psathas. New York, NY: Irvington Publishers.

Goodwin, Marjorie H. and Charles Goodwin. 2012. "Car Talk: Integrating Texts, Bodies, and Changing Landscapes." Semiotica 191:257-286.

Haugh, Michael. 2017. "Teasing." Pp. 204-218 in Handbook of Language and Humor, edited by S. Attardo. London, UK: Routledge.

Heritage, John. 1984. Garfinkel and Ethnomethodology. Cambridge: Polity Press.

Hoey, Elliott. 2018. "How Speakers Continue with Talk after a Lapse in Conversation." Research on Language and Social Interaction 51(3):329-346.

Højlund, Susanne. 2015. "Taste as a Social Sense: Rethinking Taste as a Cultural Activity." Flavour 4(1):6.

Jefferson, Gail, Harvey Sacks, and Emanuel Schegloff. 1987. "Notes on Laughter in the Pursuit of Intimacy." Pp. 152-205 in Talk and Social Organisation, edited by G. Button and J. Lee. Clevedon: Multilingual Matters.

Kääntä, Leila. 2014. "From Noticing to Initiating Correction: Students' Epistemic Displays in Instructional Interaction." Journal of Pragmatics 66:86-105.

Keevallik, Leelo. 2018. "Sequence Initiation or Self-Talk? Commenting on the Surroundings while Mucking out a Sheep Stable." Research on Language and Social Interaction 51(3):313-328.

Keisanen, Tiina. 2012. "'Uh-Oh, we Were Going there': Environmentally Occasioned Noticings of Trouble in in-Car Interaction." Semiotica 191:197-222.

Kidwell, Mardi and Don H. Zimmerman. 2007. "Joint Attention as Action." Journal of Pragmatics 39:592-611.

Laanesoo, Kirsi and Leelo Keevallik. 2017. "Noticing Breaches with Non-polar Interrogatives: Estonian Kes 'Who' Ascribing Responsibility for Problematic Conduct." Research on Language and Social Interaction 50(3):286-306.

Lancaster, Sandra and Margaret Foddy. 1988. "Self-Extensions: A Conceptualization." Journal for the Theory of Social Behavior 18(1):77-94.

Leichty, Marilyn G. 1975. "Sensory Modes, Social Activity and the Universe of Touch." Pp. 65-79 in Constructing Social Life: Readings in Behavioral Sociology from the Iowa School, edited by C. J. Couch and R. A. Hintz. Champaign, IL: Stipes Publishing Company. 
Lerner, Gene H. 2013. "On the Place of Hesitating in Delicate Formulations: A Turn-Constructional Infrastructure for Collaborative Indiscretion.” Pp. 95-134 in Conversational Repair and Human Understanding, edited by J. Sidnell, M. Hayashi, and G. Raymond. Cambridge: Cambridge University Press.

Levinson, Stephen C. 2013. "Action Formation and Ascription.” Pp. 101-130 in The Handbook of Conversation Analysis, edited by J. Sidnell and T. Stivers. Oxford: John Wiley and Sons.

Maynard, Douglas W. and Don H. Zimmerman. 1984. "Topical Talk, Ritual and the Social Organization of Relationships." Social Psychology Quarterly 47(4):301-316.

Miller, Dan E. 2011. "Toward a Theory of Interaction: The Iowa School." Symbolic Interaction 34(3):340-348.

Miller, Dan E., Robert A. Hintz, and Carl J. Couch. 1975. "The Elements and Structure of Openings." The Sociological Quarterly 16(4):479-499.

Mondada, Lorenza. 2012. "Embodied Action and Joint Attention in Extended Sequences." Pp. 279-296 in Interaction and Everyday Life: Phenomenological and Ethnomethodological Essays in Honor of George Psathas, edited by H. Nasu and F. Chaput Waksler. Lanham, MD: Lexington Books.

Mondada, Lorenza. 2019. "Contemporary Issues in Conversation Analysis: Embodiment and Materiality, Multimodality and Multisensorality in Social Interaction." Journal of Pragmatics 145:47-62.

Moore, Chris and Philip J. Dunham, eds. 1995. Joint Attention: Its Origins and Role in Development. Hillsdale, NJ: Lawrence Erlbaum Associates.

Pillet-Shore, Danielle. 2006. "Weighing in Primary-Care Nurse-Patient Interactions." Social Science \& Medicine 62:407-421.

Pillet-Shore, Danielle. 2008. Coming Together: Creating and Maintaining Social Relationships through the Openings of Face-to-Face Interactions. PhD dissertation: Department of Sociology, University of California, Los Angeles.

Pillet-Shore, Danielle. 2010. "Making Way and Making Sense: Including Newcomers in Interaction." Social Psychology Quarterly 73(2):152-175.

Pillet-Shore, Danielle. 2012. "Greeting: Displaying Stance through Prosodic Recipient Design." Research on Language and Social Interaction 45(4):375-398.

Pillet-Shore, Danielle. 2015a. "Compliments." in The International Encyclopedia of Language and Social Interaction (1st Ed.), edited by K. Tracy, C. Ilie, and T. Sandel. Hoboken, NJ: John Wiley.

Pillet-Shore, Danielle. 2015b. "Complaints." in The International Encyclopedia of Language and Social Interaction (1st ed.), edited by K. Tracy, C. Ilie, and T. Sandel. Hoboken, NJ: John Wiley.

Pillet-Shore, Danielle. 2015c. "Being a 'Good Parent' in Parent-Teacher Conferences." Journal of Communication 65(2):373-395.

Pillet-Shore, Danielle. 2016. "Criticizing Another's Child: How Teachers Evaluate Students during Parent-Teacher Conferences." Language in Society 45:33-58.

Pillet-Shore, Danielle. 2017. "Preference Organization." in Oxford Research Encyclopedia of Communication, edited by J. Nussbaum. Oxford, UK: Oxford University Press. https://doi.org/10 .1093/acrefore/9780190228613.013.132.

Pillet-Shore, Danielle. 2018a. "How to Begin." Research on Language and Social Interaction 51(3):213-231.

Pillet-Shore, Danielle. 2018b. "Arriving: Expanding the Personal State Sequence." Research on Language and Social Interaction 51(3):232-247.

Pomerantz, Anita. 1984. "Agreeing and Disagreeing with Assessments: Some Features of Preferred/Dispreferred Turn Shapes." Pp. 57-101 in Structures of Social Action: Studies in Conversation Analysis, edited by J. M. Atkinson and J. Heritage. Cambridge: Cambridge University Press. 
Pomerantz, Anita and Jenny Mandelbaum. 2005. "Conversation Analytic Approaches to the Relevance and Uses of Relationship Categories in Interaction." Pp. 149-171 in Handbook of Language and Social Interaction, edited by K. L. Fitch and R. E. Sanders. Mahwah, NJ: Lawrence Erlbaum Associates.

Robinson, Jeffrey and Galina Bolden. 2010. "Preference Organization of Sequence-Initiating Actions: The Case of Explicit Account Solicitations." Discourse Studies 12(4):501-533.

Sacks, Harvey. 1992. Lectures on Conversation [1964-1972] (Vol. 1 and 2), Edited by G. Jefferson. Cambridge: Blackwell Publishers.

Scheff, Thomas. 2005. "Looking-Glass Self: Goffman as Symbolic Interactionist.” Symbolic Interaction 28(2):147-166.

Schegloff, Emanuel A. and Harvey Sacks. 1973. "Opening Up Closings.” Semiotica 8:289-327.

Schegloff, Emanuel A.. 1986. "The Routine as Achievement." Human Studies 9:111-151.

Schegloff, Emanuel A. 1988. "Goffman and the Analysis of Conversation." Pp. 89-135 in Erving Goffman: Exploring the Interaction Order, edited by P. Drew and A. J. Wootton. Cambridge: Polity Press.

Schegloff, Emanuel A. 2007. Sequence Organization in Interaction: A Primer in Conversation Analysis, Vol. 1. Cambridge, UK: Cambridge University Press.

Sidnell, Jack. 2010. Conversation Analysis: An Introduction. Malden, MA: Wiley-Blackwell.

Steensig, Jakob. 2015. "Registering the Material World." in Presented at the International Institute for Ethnomethodology and Conversation Analysis Conference, August 5. Kolding: Denmark.

Stivers, Tanya and Federico Rossano. 2010. "Mobilizing Response." Research on Language and Social Interaction 43(1):3-31.

Szymanski, Margaret H. 1999. "Re-engaging and Disengaging Talk in Activity." Language in Society 28(1):1-23.

Tomasello, Michael. 1995. "Joint Attention as Social Cognition." Pp. 103-130 in Joint Attention: Its Origins and Role in Development, edited by C. Moore and P. J. Dunham. Hillsdale, NJ: Lawrence Erlbaum Associates.

Tomasello, Michael and Michael Jeffrey Farrar. 1986. "Joint Attention and Early Language." Child Development 57(6):1454-1463.

Vannini, Phillip, Guppy Ahluwalia-Lopez, Dennis Waskul, and Simon Gottschalk. 2010. "Performing Taste at Wine Festivals: A Somatic Layered Account of Material Culture.” Qualitative Inquiry 16(5):378-396.

Wilkinson, Sue and Celia Kitzinger. 2006. "Surprise as an Interactional Achievement: Reaction Tokens in Conversation.” Social Psychology Quarterly 69(2):150-182.

\section{ABOUT THE CONTRIBUTOR(S)}

Danielle Pillet-Shore (Ph.D., University of California, Los Angeles) is a sociologist, conversation analyst and Associate Professor of Communication at the University of New Hampshire. She examines video-recorded naturally occurring interactions between people coming together to socialize and/or work, focusing on how people create and maintain their social and professional relationships in everyday life. She is currently investigating how both previously acquainted and unacquainted parties open their face-to-face interactions across a wide variety of settings, as well as how primary school teachers and their students' parents interact during parent-teacher conferences. Dr Pillet-Shore guest edited Opening and Maintaining Face-to-Face Interaction (special issue of Research on Language and Social Interaction 2018). 